Article

\title{
Fuzzy TOPSIS-EW Method with Multi-Granularity Linguistic Assessment Information for Emergency Logistics Performance Evaluation
}

\author{
Yanwu Liu ${ }^{1}$, Liang $\mathrm{Li}^{1}$, Yan Tu ${ }^{1} * \mathbb{D}$ and Yanlan Mei ${ }^{2,3}$ \\ 1 School of Safety Science and Emergency Management, Wuhan University of Technology, Wuhan 430070, \\ China; yanwu_liu@whut.edu.cn (Y.L.); liliang1996@whut.edu.cn (L.L.) \\ 2 School of Resource and Environmental Engineering, Wuhan University of Science and Technology, \\ Wuhan 430081, China; meiyanlan@wust.edu.cn \\ 3 School of Management, Wuhan University of Science and Technology, Wuhan 430065, China \\ * Correspondence: tuyan1988@whut.edu.cn
}

Received: 18 July 2020; Accepted: 9 August 2020; Published: 10 August 2020

\begin{abstract}
The operation of emergency logistics plays a prominent role in reducing the consequences of disasters. Based on the establishment of a comprehensive evaluation system with the whole period of the disaster cycle that covers emergency preparation, response, and recovery, this paper proposes a fuzzy-symmetrical Technique for Order Preference by Similarity to Ideal Solution-Entropy Weight (TOPSIS-EW) method with multi-granularity linguistic assessment (MGLA) information to evaluate the performance of emergency logistics. Furthermore, the proposed evaluation method is employed to evaluate the performance of emergency logistics in Wenchuan earthquake, five worst-hit regions (i.e., Wenchuan County, Beichuan County, Qingchuan County, Mianzhu City, Shifang City) were ranked as V, III, I, II, IV, respectively. Finally, the effectiveness and reliability of the method are verified by comparison with the other two related methods and a sensitivity analysis. Based on the comprehensive evaluation results, some specific managerial suggestions are proposed to improve the emergency logistics capacity.
\end{abstract}

Keywords: emergency logistics performance evaluation; hesitant fuzzy linguistic set; TOPSIS; entropy weight; multi-granularity linguistic

\section{Introduction}

In recent years, unconventional emergencies occur frequently and this phenomenon causes great loss to people's life, the safety of their property, and also affects the development of society. The ability of pre-disaster prediction and prevention, emergency rescue in disasters, and post-disaster disposal plays an important role in reducing loss [1]. Emergency logistics as a response to emergencies is particularly important, which is related to whether the lives and properties of the victims can be saved. If the role of emergency logistics cannot be effectively played, it may seriously affect the "golden 72-hour" life-saving work and worsen disaster consequences.

Despite the rapid economic and technological development of the world, countries or regions around the world remain vulnerable to a number of emergencies such as natural disasters, accidents, and public health emergencies. As is known to all, the frequent occurrence of emergencies has caused huge loss of life and property all over the world. Disastrous events during the past two decades include the Iraq war (2003), SARS in China (2003), the tsunami in Indonesia regions (2004), Hurricane Katrina in America (2005), the Bangladesh cyclone Sidr (2007), the Wenchuan earthquake in China (2008), etc. All of these emergencies have caused massive disruption to people's lives, requiring the delivery and distribution of large quantities of relief supplies in a short period of time. 
When unexpected disasters crop up, relief operations are carried out in the initial response phase, and logistics support operations need to last longer to meet the basic living needs of survivors in the affected areas. Therefore, the performance of emergency logistics plays a vital role in disaster mitigation, it is very necessary to make a reasonable evaluation of the corresponding logistics.

The multi-criteria decision making (MCDM) method has been widely used in the area of logistics [2,3], and while there are few studies on emergency decision-making [4], previous emergency logistics evaluation research has tended to focus on emergency logistic planning or emergency logistic management $[5,6]$. To the authors' best knowledge, performance evaluations of emergency logistics are rare. In addition, when evaluating emergency logistics, researchers usually take into account the logistics center capabilities, the logistics system path planning, the material supplier selection [7,8], and provide some suggestions for improving actual emergency logistics problems [9]. However, emergency logistics is a complex system, which needs to take into account the supply capacity and coordination capacity of human, material, capital, transportation from a system perspective. Therefore, the basic idea of this paper is to consider the whole components of emergency logistics to carry out performance evaluation.

Because unconventional emergencies is an unstructured or semi-structured problem, most of the studies are conducted considering the internal branches of the emergency logistics system, for example, Sahu (2016) and $\mathrm{Hu}$ (2019) studied the selection of suppliers for disaster relief supplies $[7,10]$. Bozorgi-Amiri (2016) studied the location and route selection of disaster relief logistics [11]. Liu (2017) evaluated the integrity of emergency supplies distribution [12]. Some researchers tried to establish an indicators system for the evaluation of the whole emergency logistics system, for example, Gong (2012) evaluated the emergency logistics system reliability and analyzed the hypothetical examples [13]. Guan (2017) proposed an evaluation model for earthquake relief emergency logistics capacity [14]. However, the indicators system of these researches mainly focuses on the emergency response stage and rarely considers the pre-disaster prediction and post-disaster reconstruction. To solve this problem, the indicators system established in this study considers the entire disaster cycle, which covers emergency preparation, response, and recovery.

In recent decades, there have been a lot of evaluation methods for emergency logistics performance evaluation [15], in which the MCDM method has been broadly employed [16,17], it refers to selecting the optimal scheme or sorting under consideration of multiple criteria. As an MCDM method, TOPSIS symmetrical technique has been extensively used in scheme selection and performance evaluation $[18,19]$. The optimal scheme selected by the TOPSIS method is based on minimizing the distance from the positive ideal point and maximizing the distance from the negative ideal point, so it is very suitable for study with both benefit indicators and cost indicators. In addition, the TOPSIS method can be operated easily when there are many criteria and alternatives [20-22]. Moreover, the advantage of the TOPSIS method is that it can be used to deal with different indicators with different dimensions. In the proposed evaluation indicator system of the emergency logistics performance, many kinds of indicators with different dimensions are considered. Furthermore, the relative closeness calculation of the TOPSIS method depends on the range of available alternatives. Emergencies are abrupt and uncertain, and their destructiveness is also caused by the complexity of their influencing factors. As a result, the public is unable to obtain the optimal results when faced with the losses caused by huge disasters. Therefore, the TOPSIS method is applicable to the evaluation of emergencies, ranking the performance of emergency logistics in various regions, based on which some suggestions can be put forward for improving the ability to respond to emergencies. In addition, in the TOPSIS method, the determination of indicator weights is the most critical part. Experts' preferences are difficult to measure using determined values, the hesitant fuzzy linguistic set, closer to human cognition expressions [23-25], is used in this paper to describe the experts' judgments on the importance of the indicators. Moreover, maximum group consensus and minimum hesitant degree [26,27], which can obtain group consistency and improve decision credibility [18], are considered to get the experts' weights. Based on this, the weighted average operator is used for obtaining the indicator weight. 
However, due to its inherent subjectivity and ambiguity, the application of this method has some limitations. The entropy weight $(\mathrm{EW})$ method can fully mine the information contained in the original data, the smaller the entropy value, the smaller the degree of disorder in the system, and the higher the weight. Therefore, the objective weights of the EW method can be used to adjust the subjective weights to get more practical results [2]. Furthermore, there exist some indicators in the system that are difficult to quantify, the multi-granularity linguistic assessment (MGLA) approach, which can enhance the elasticity and dependability of processing multifarious linguistic expressions [28-31], is applied to express qualitative information as linguistic variables in the processing of some indicators hard to quantify. In this case, a fuzzy TOPSIS-EW method with MGLA information is put forward in this paper for performance evaluation of emergency logistics. Table 1 summarizes the main facing challenges and the solving strategies adopted in this study.

Table 1. Challenges faced and strategies adopted in this paper.

\begin{tabular}{ll}
\hline \multicolumn{1}{c}{ Challenges Faced } & \multicolumn{1}{c}{ Strategies Adopted } \\
\hline Selection of evaluation indicators & Considering the whole cycle of disasters \\
Quantification of some indicators & MGLA method \\
Determination of expert weights & Maximum group consensus and minimum hesitation \\
Determination of indicator weight & Subjective-objective weighing of the method \\
Comparison of regional performance levels & Fuzzy TOPSIS method \\
\hline
\end{tabular}

The remainder of this paper is structured in the following way. The key problem statement is stated in Section 2. Section 3 introduces the comprehensive evaluation methodology, which includes the overall framework, the indicators description, the main steps of the MGLA method, the weights determination method, and the TOPSIS method. In Section 4, the proposed method is employed to evaluate the emergency logistics performance level of several worst-hit districts in Wenchuan earthquake in China, in which a comparison analysis with the TOPSIS method with equal expert weights and the TOPSIS-EW method is conducted along with a sensitivity analysis demonstrating the influence of decision-making strategy. Moreover, the deficiencies in some emergency logistics systems are pointed out and the directions for improvement are presented in this section. Section 5 presents the conclusions with a summary and gives the future research direction.

\section{Key Problem Statement}

\subsection{Emergency Logistics System}

As shown in Figure 1. Emergency response procedures include three stages: preparedness, monitoring, and early warning; rescue and disposal, and post-emergency recovery and reconstruction [32]. The explanation for the three stages is as follows:

- Emergency preparedness is a key link to prevent the occurrence of emergencies, monitor risks and make preparations for reducing the consequences of disasters so that the government and the people form the necessary emergency capacity [33].

- Emergency response is an emergency action, the main function is to send rescue teams and social forces to the disaster areas in a very short time, deliver and deploy rescue materials and conduct other activities in the disaster area [9], so the timeliness and coordination of emergency response largely determine the performance of this stage.

- Post-disaster recovery and reconstruction refers to the ability to ensure the basic life of the masses and quickly restore the order of life in the affected areas.

The evaluation of the three stages can realize the performance evaluation of the emergency logistics system formed by each component in emergency logistics. If we only evaluate materials supply losing sight of the other two stages, its connection with reasonable materials distribution may not be considered, resulting in redundancy or shortage of local materials. If we only take into account 
emergency response ignoring preparedness and post-disaster disposal, it will lead to failure to consider the limitation of emergency funds and supplies, which will bring a heavy burden to emergency rescue. If we only consider post-disaster reconstruction and recovery, it will cause great pressure on the government due to the type and severity of emergencies.

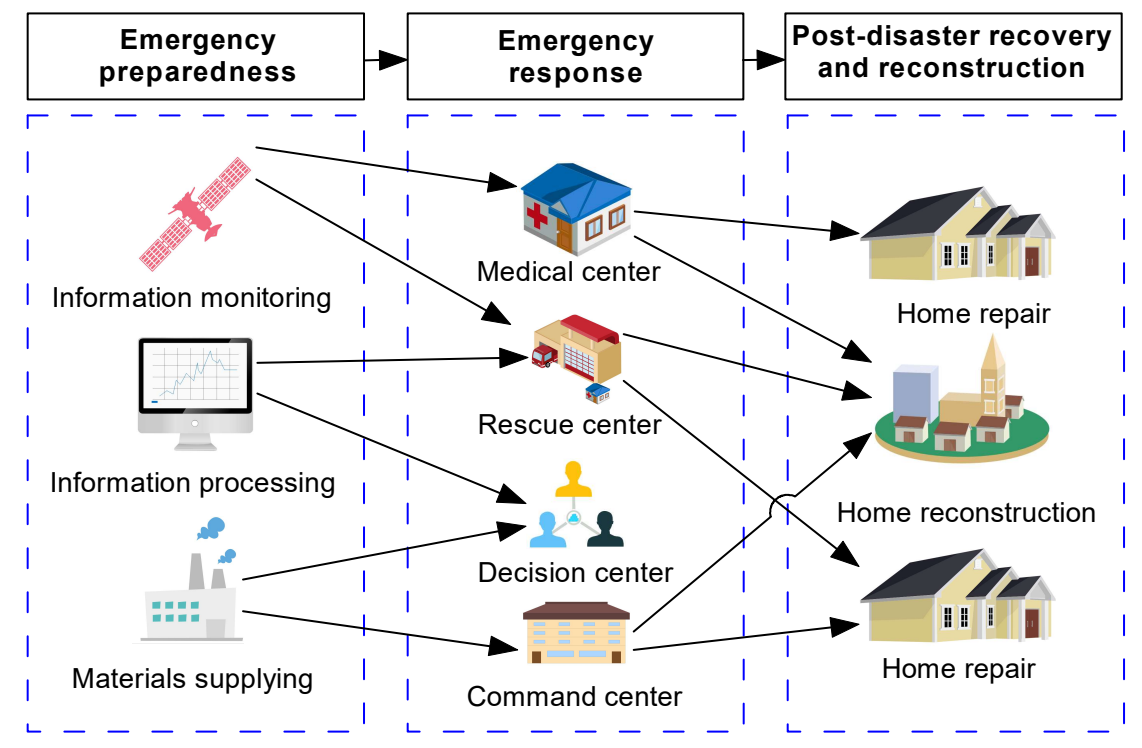

Figure 1. Emergency response procedures.

\subsection{Evaluation Indicator System}

For considering the whole period of the disaster cycle and summarizing from previous evaluation studies [13,14], the evaluation indicator system established in this paper is shown in Figure 2. The emergency logistics performance evaluation indicators system can be divided into four subsystems: information processing (denoted as $A_{1}$ ), logistics operation (denoted as $A_{2}$ ), organization and coordination (denoted as $A_{3}$ ) and post-disaster response (denoted as $A_{4}$ ). Three aspects are included in $A_{1}$, i.e., information collection and analysis (denoted as $B_{1}$ ), natural disaster prediction (denoted as $B_{2}$ ), and comprehensive database (denoted as $B_{3}$ ). For $A_{2}$, four aspects are involved, i.e., material acquisition (denoted as $C_{1}$ ), material reserve (denoted as $C_{2}$ ), material transport (denoted as $C_{3}$ ), and material distribution (denoted as $C_{4}$ ). Three aspects are considered for $A_{3}$, i.e., arrange and coordinate (denoted as $D_{1}$ ), emergency fund reserves (denoted as $D_{2}$ ), and mobilization (denoted as $D_{3}$ ). For $A_{4}$, two aspects are embraced, i.e., immediate effect (denoted as $H_{1}$ ) and recovery construction (denoted as $\mathrm{H}_{2}$ ). For each subsystem, the selection of specific evaluation indicators follows the principles below [34]:

- The accuracy principle. The definitions of objective indicators should be accurate and the source of data should be reliable. The acquisition of subjective indicators should meet the requirements of comprehensive evaluation techniques.

- The integrity principle. The evaluation indicator system should not only include the contents of prediction, response and recovery, but also consider the organization, coordination and information transmit in the process of emergency logistics operations.

- The easy-to-operate principle. The indicators are clear in definition, and the data is of good accessibility, which can fully show the actual level of emergency logistics, and make for the improvement of performance.

- The independent principle. Indicators should be independent of each other, avoiding duplicate evaluations.

- The comparable principle. To make the evaluation results about indicators comparable in different alternatives, the definitions and measurement criteria of indicators should be normalized. 


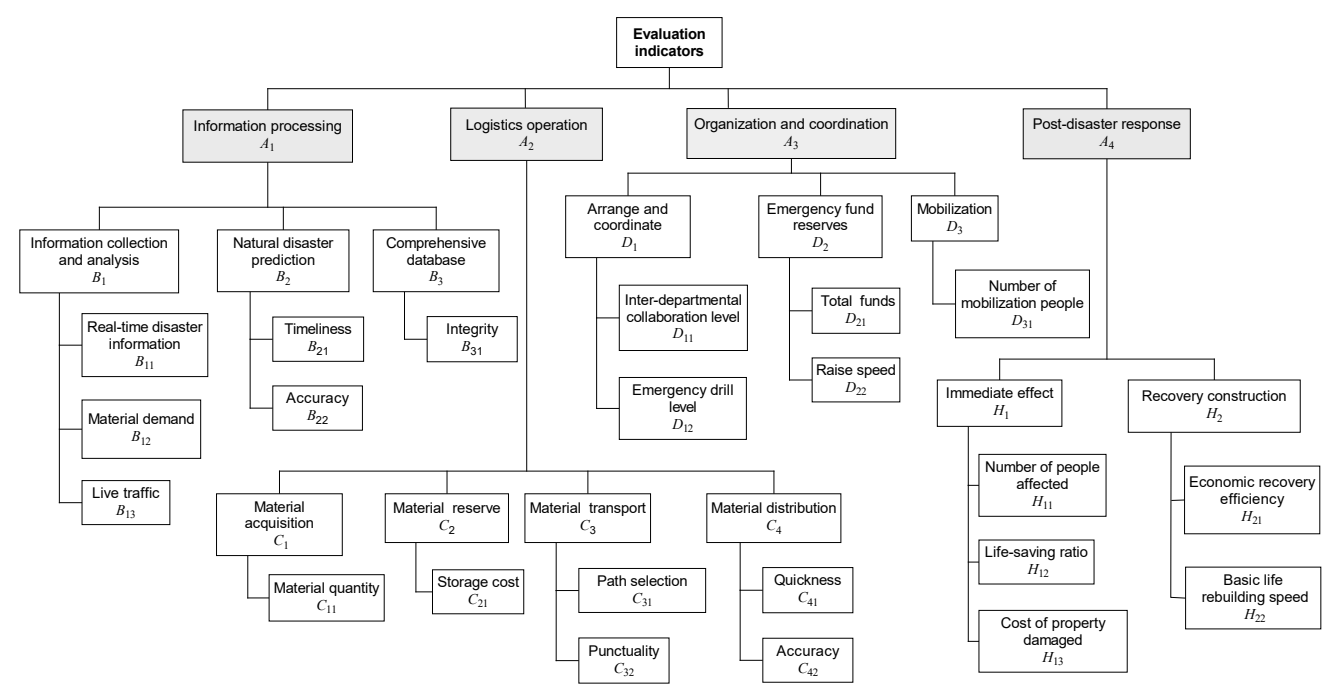

Figure 2. Evaluation indicator system.

\section{Evaluation Methodology}

\subsection{Overall Framework}

The overall framework is presented below. There are $u$ evaluators, $E_{m}(m=1,2, \ldots, u)$ is the $m$ th evaluator; $p$ indicators, $A_{h}(h=1,2, \ldots, p)$ is the $h$ th indicator; and $q$ regions to be evaluated, $R_{i}(i=1,2, \ldots, q)$ is $i$ th region. This study describes the experts' judgments on the importance degrees of indicators by employing hesitant fuzzy linguistic sets and then both group consensus maximization and hesitant degree minimization are considered to determine the experts' weights. The weighted average operator [18] is combined with the EW method to obtain the indicator weights. Moreover, the MGLA method is utilized to solve the quantification problem of some indicators. After collecting the data of all indicators, the TOPSIS method is utilized to sort and obtain the final ranking of the regions (i.e., alternatives). The overall framework of the evaluation method is shown in Figure 3.

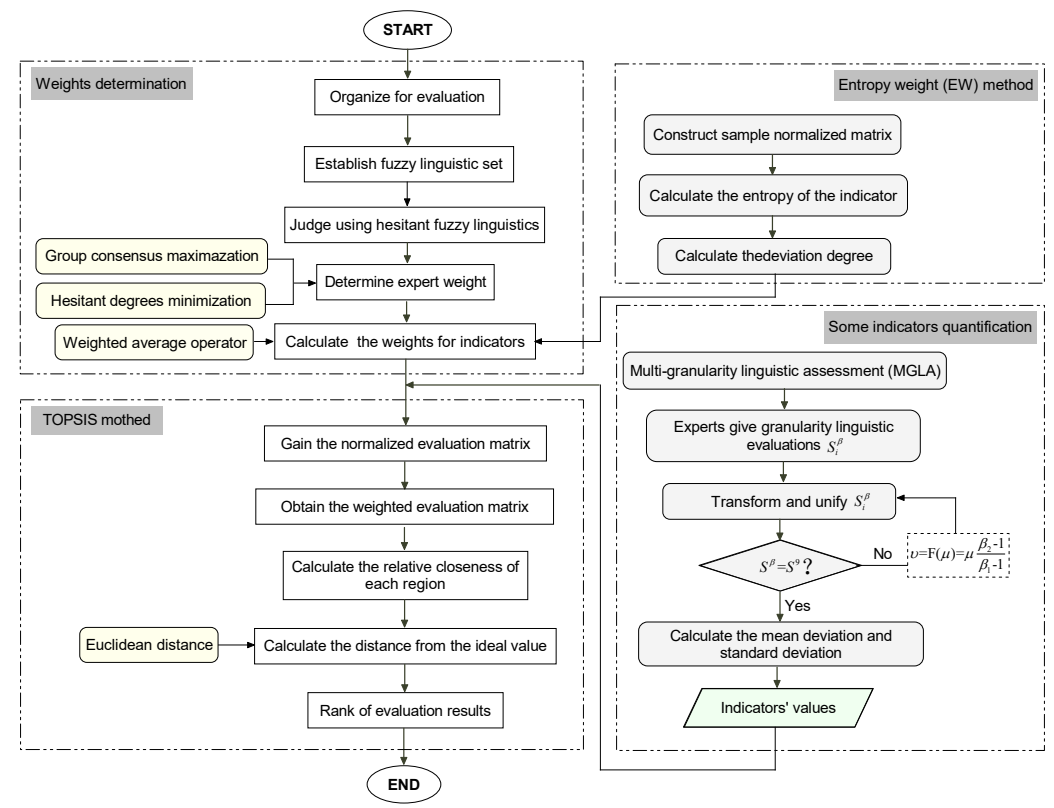

Figure 3. The general framework of the evaluation methodology. 


\subsection{Indicators Description}

The indicators of emergency logistics performance evaluation can be divided into 4 subsystems: information processing (denoted as $A_{1}$ ), logistics operation (denoted as $A_{2}$ ), organization and coordination (denoted as $A_{3}$ ), and post-disaster response (denoted as $A_{4}$ ).

\subsubsection{Information Processing}

This paper mainly considers information processing from three aspects: information collection and analysis (denoted as $B_{1}$ ), natural disaster prediction (denoted as $B_{2}$ ), and comprehensive database (denoted as $B_{3}$ ) [35]. The detailed description is as follows.

The real-time disaster information (denoted as $B_{11}$ ) is used to reflect whether the local government department can get the disaster situation in time after the disaster occurs in the disaster area [36]. Therefore, the time required to initiate an emergency response is used to measure this indicator.

$$
B_{11}=Z_{1}-Z_{0},
$$

where $Z_{0}$ is the time of the earthquake eruption, $Z_{1}$ is the time required to initiate an emergency response.

To provide more reliable and accurate real-time information of the demand for emergency supplies in disaster areas, to predict and calculate the material demand (denoted as $B_{12}$ ), to facilitate decision-makers to conduct scientific and reasonable emergency supplies scheduling. In this paper, the demand for tents after the disaster is used to measure this indicator.

Whether decision makers can timely grasp real-time road conditions has an important impact on the path selection and transportation of emergency supplies, as well as personnel scheduling. Live traffic (denoted as $B_{13}$ ) affects the path selection. If accurate information cannot be mastered, the subsequent path selection may no longer be optimized, and path adjustment is required.

The timeliness of disaster prediction (denoted as $B_{21}$ ) mainly refers to the timely acquisition of data and early warning of disasters to facilitate the prediction and prevention of disasters. Control in the initial stage of a disaster can minimize the damage. The immediacy of disaster prediction can be reflected by the time between the earthquake eruption and the government getting initial information about the disaster.

$$
B_{21}=Z_{2}-Z_{0},
$$

where $Z_{2}$ is the time of the government to get initial information about the disaster.

The accuracy of disaster prediction (denoted as $B_{22}$ ) is mainly influenced by the accuracy of information prediction and the accurate judgment of information by professionals.

A well-developed emergency database can provide policymakers with information to make more accurate decisions about disasters. The database is the collection and integration of historical data to provide reference data for disaster prevention and prediction. Therefore, the integrity of the emergency database (denoted as $B_{31}$ ) can greatly improve the ability to cope with disasters [37]. The number of disaster information collected within $24 \mathrm{~h}$ is used to measure this indicator.

\subsubsection{Logistics Operation}

Emergency logistics operation can ensure survivors of disaster-stricken regions with relief materials (such as medical supplies, water, food), provide the necessary financial support in need and contribute to post-disaster reconstruction and rehabilitation activities. In general, the emergency logistics system consists mainly of elements such as the acquisition, storage, and transportation and allocation of emergency supplies $[38,39]$. The goal of emergency logistics operation is to integrate and make the best of emergency supplies, to pursue the fastest time efficiency within the acceptable range of economic input, deliver the materials to the designated place as soon as possible, and reduce the consequences of disasters. 
In this paper, the quantity of materials (denoted as $C_{11}$ ) is the standard to measure whether the emergency resources in the disaster area can reach the balance between supply and demand. This indicator is based on the number of relief living tents delivered to the disaster area on 25 May 2008.

Reasonable emergency supplies reserve is a powerful guarantee to cope with unexpected disasters. Therefore, it is of great importance to reserve emergency supplies and analyze the reasonable demand for emergency supplies in case of emergencies. The emergency supplies storage plan should be of operability ad rationality, paying attention to the sustainability, economy, and balance in the material storage process [40].

By controlling the storage cost of emergency supplies [41], emergency funds can be allocated more effectively. The cost of storing a single tent is about 10 percent of the market price, so the storage cost is 40 yuan for each tent. Then the storage cost (denoted as $C_{21}$ ) can be defined as

$$
C_{21}=B_{12} \times 40 .
$$

Transportation and allocation are the core links of emergency logistics operations to convey relief supplies and rescue staff to disaster areas. In emergency situations, the quantity of emergency relief supplies is relatively limited, which requires decision-makers to formulate the optimal route for the transportation of relief supplies with maximum social value.

The path selection (denoted as $C_{31}$ ) directly affects the fastest time for the delivery of relief supplies to the disaster-affected areas, and sometimes it is necessary to open a green channel to save transportation time. In this paper, the road damage rate of the most influential path choice is used to measure this indicator.

Even if the path selection above is optimal, the transportation process will still be affected by the real-time road conditions and other conditions to reach the destination time. Let $N_{o}$ denote the on-time delivery times, and $N_{d}$ denotes the total number of deliveries, the basic form for punctuality rate (denoted as $C_{32}$ ) can be expressed as follows:

$$
C_{32}=\frac{N_{o}}{N_{d}}
$$

Emergency relief material delivery from local distribution centers to disaster-affected beneficiaries measure the last kilometer of material delivery [42] with quickness (denoted as $C_{41}$ ) and accuracy (denoted as $\mathrm{C}_{42}$ ).

\subsubsection{Organization and Coordination}

When an emergency occurs, a number of social groups or organizations organized by the government participate in the emergency relief work, bringing more relief resources to the affected areas and people. To ensure the efficient and orderly participation of the emergency rescue work, the central and local governments should coordinate all aspects of the work, such as the establishment of emergency funds and emergency departments.

The level of inter-departmental collaboration (denoted as $D_{11}$ ) reflects the decision-making ability and management ability of the government. Good inter-organizational coordination can make efficient use of human and material resources and save rescue time. Therefore, it is necessary to set up corresponding working groups, such as the emergency rescue team, the medical rescue team, the communication support team, etc. This paper is represented by the number of working response groups established after the earthquake.

The emergency drill level (denoted as $D_{12}$ ) is the response to the emergency situation shown by the simulation training in different situations. Practice has proven that regular emergency drills can reduce personnel casualties and property losses and restore normal conditions for the disaster-hit areas as soon as possible [43].

$$
D_{12}=Z_{3}-Z_{0}
$$


where $Z_{3}$ is the time of government to get initial information about the damage.

Emergency fund (denoted as $D_{21}$ ) is the important foundation for the rescue activities, there should be enough funds and reasonable allocation of use, so the speed of fundraising (denoted as $D_{22}$ ) should be as fast as possible.

After the disaster, all the departments, military, medical, social volunteers, and other supporting forces are mobilized to help the disaster regions. Consequently, the number of mobilization (denoted as $D_{31}$ ) to reflect the situation of mobilization after the disaster. The number of armed police officers and soldiers supporting the disaster areas within three days after the earthquake to represent the mobilization force.

\subsubsection{Post-Disaster Response}

As most emergencies will have serious consequences, such as damaging infrastructure and buildings in the affected areas, post-disaster reconstruction is a difficult and long-term work.

This paper considers using the number of injuries and deaths (denoted as $H_{11}$ ) to assess the severity of the disaster.

Two indicators are used to evaluate the relief effect in the disaster area. First, Life-saving ratio (denoted as $H_{12}$ ) is defined as

$$
H_{12}=\frac{N R}{T N V} \times 100 \%,
$$

where $N R$ is the number of rescued, $T N V$ is the total number of victims.

And the cost of property damaged (denoted as $\mathrm{H}_{13}$ ) reflect the damage in the affected areas.

The people in the disaster-hit areas suffer heavy losses after the major disaster and must speed up reconstruction to restore normal life in the disaster-hit areas. The economic recovery efficiency (denoted as $\mathrm{H}_{21}$ ) reflects the rate of economic recovery, and on the other hand, the basic life rebuilding speed (denoted as $\mathrm{H}_{22}$ ) is measured by the time the graduating students return to class.

\subsection{MGLA Approach}

Due to the uncertainty and complexity of earthquake occurrence, direct data cannot be obtained for some indicators in real life, Therefore, it is necessary to conduct an expert evaluation on these indicators, this paper uses the MGLA approach to solve the quantification of these indicators [28,29].

Step 1. At times, the experts employ multi-granularity linguistic term sets to express their own judgment information. In this case, let $S^{\beta}=\left\{S_{y}^{\beta} \mid y \in\{0,1, \ldots, \beta-1\}\right\}$ be the $\beta$ th pre-established confined and completely ordered linguistic term set, where $\beta$ is called the granularity of $S^{\beta}, S_{y}^{\beta}$ denotes the $y$ th linguistic term of set $S^{\beta}$. The judgment of each individual expert can be fully expressed by the utilization of the linguistic label set of granularity.

Step 2. Considering these original linguistic terms are obtained from different experts with different linguistic granularities, they should be unified first. This study utilizes some transformation functions to unify the derived multi-granularity linguistic labels into a consistent linguistic term set. With regard to any two linguistic term sets $\bar{S}^{\left(\beta_{1}\right)}=\left\{S_{\mu}^{\left(\beta_{1}\right)} \mid \mu \in\left[0, \beta_{1}-1\right]\right\}$ and $\bar{S}^{\left(\beta_{2}\right)}=\left\{S_{v}^{\left(\beta_{2}\right)} \mid v \in\right.$ $\left.\left[0, \beta_{2}-1\right]\right\}$, the transformation functions between them are presented below [44]:

$$
\begin{gathered}
F: S^{\left(\beta_{1}\right)} \longrightarrow S^{\left(\beta_{2}\right)}, \\
v=F(\mu)=\mu \frac{\beta_{2}-1}{\beta_{1}-1}, \\
F^{-1}: S^{\left(\beta_{2}\right)} \longrightarrow S^{\left(\beta_{1}\right)}, \\
\mu=F^{-1}(v)=v \frac{\beta_{1}-1}{\beta_{2}-1} .
\end{gathered}
$$


Using Equations (7)-(10), the linguistic term sets in $\bar{S}^{\left(\beta_{1}\right)}$ and $\bar{S}\left(\beta_{2}\right)$ can be made consistent without loss of decision information. It is noteworthy that the selection of any given linguistic term sets does not change the end results, therefore the above method can be employed to transform and unify the multi-granularity linguistic comparison matrices based on the information given by the experts.

Step 3. Conducting improved standard and mean deviations method [44]. Let $S_{\eta}, S_{\theta} \in S^{\beta}$ be two linguistic variables, the deviation between $S_{\eta}$ and $S_{\theta}$ is expressed as $d\left(S_{\eta}, S_{\theta}\right)=|| S_{\eta}-S_{\theta}||=|\eta-\theta|$. To expert $e_{k}$ and indicator $A_{j}$, the standard deviation between region $R_{i}$ and others is as follows [45]:

$$
\begin{aligned}
G_{j}^{(k)} & =\sqrt{\frac{1}{q} \sum_{i=1}^{q}\left(\left\|x_{i j}^{(k)} w_{j}^{(k)}-\frac{1}{q} \sum_{a=1}^{q} x_{a j}^{(k)} w_{j}^{(k)}\right\|\right)^{2}}=w_{j}^{(k)} \sqrt{\frac{1}{q} \sum_{i=1}^{q}\left(d\left(x_{i j}^{(k)}, x_{j}^{(k)}\right)\right)^{2}} \\
& =w_{j}^{(k)} \tau_{j}^{(k)}, j \in[1, p]
\end{aligned}
$$

where

$$
\tau_{j}^{(k)}=\sqrt{\frac{1}{q} \sum_{i=1}^{q}\left(d\left(x_{i j}^{(k)}, x_{j}^{(k)}\right)\right)^{2}},
$$

where $x_{i j}^{(k)}$ denotes the judgement information given by expert $e_{k}$ about $j$ th indicator of $R_{i}$ region, then $x_{j}^{(k)}=\sqrt{\frac{1}{q} \sum_{i=1}^{q} x_{i j}^{(k)}}$ denotes the mean value of indicator $A_{j}$ given by expert $e_{k} . d\left(x_{i j}^{(k)}, x_{j}^{(k)}\right)$ represents the deviation of the mean value $x_{j}^{(k)}$ to the attribute value $x_{i j}^{(k)}$ of the region $R_{i}$ for the indicator $A_{j}$ of the expert $e_{k}$. Then $G_{j}^{(k)}$ denotes the standard deviation for the indicator $A_{j}$ of expert $e_{k}$. The mean deviation can be expressed as

$$
V_{j}^{(k)}=\frac{1}{q} \sum_{i=1}^{q}\left\|x_{i j}^{(k)} w_{j}^{(k)}-\frac{1}{q} \sum_{a=1}^{q} x_{a j}^{(k)} w_{j}^{(k)}\right\|=w_{j}^{(k)} \frac{1}{q} \sum_{i=1}^{q} d\left(x_{i j}^{(k)}, x_{j}^{(k)}\right)=w_{j}^{(k)} \varsigma_{j}^{(k)}, \quad j \in[1, p],
$$

where

$$
\varsigma_{j}^{(k)}=\frac{1}{q} \sum_{i=1}^{q} d\left(x_{i j}^{(k)}, x_{j}^{(k)}\right),
$$

where $x_{j}^{(k)}=\frac{1}{q} \sum_{a=1}^{q} x_{a j}^{(k)}$ denotes the mean value of the indicator $A_{j}$ given by expert $e_{k} \cdot d\left(x_{i j}^{(k)}, x_{j}^{(k)}\right)$ denotes the deviation of the mean value $x_{j}^{(k)}$ to the attribute value $x_{i j}^{(k)}$ of region $R_{i}$ for indicator $A_{j}$ of the expert $e_{k}$. Then $V_{j}^{(k)}$ denotes the mean deviation for indicator $A_{j}$ of expert $e_{k}$.

Step 4. Based on the above analysis, maximizing the total mean and standard deviation of all the evaluation indicators to determine the weighting vector $w$. The objective function is established below:

$$
\begin{aligned}
& \max F(w)=\sum_{j=1}^{p}\left(\xi G_{j}^{(k)}+\varrho V_{j}^{(k)}\right), \\
& \text { s.t. }\left\{\begin{array}{l}
\sum_{j=1}^{p} w w_{j}^{(k)^{2}}=1, w_{j}^{(k)} \geq 0, j=1,2, \ldots, p, \\
\xi+\varrho=1, \xi \geq 0, \varrho \geq 0,
\end{array}\right.
\end{aligned}
$$

where $\xi$ and $\varrho$ denote the preferences of the experts, $\varrho=0$ denotes the experts take into account the standard deviation while not the mean deviation, $\xi=0$ denotes the experts take into account the mean deviation while not the standard deviation, then $\xi, \varrho \neq 0$ denotes the experts take into account both 
the mean and standard deviations. Therefore the following model is determined when taking into account both the mean and standard deviations:

$$
\begin{aligned}
& \max F(w)=\sum_{j=1}^{p} w_{j}^{(k)}\left(\xi \tau_{j}^{(k)}+\varrho s_{j}^{(k)}\right) \\
& \text { s.t }\left\{\begin{array}{l}
w_{j} \geq 0, j=1,2, \ldots, p, \\
\sum_{j=1}^{p} w_{j}^{(k)^{2}}=1, \\
\xi+\varrho=1, \xi \geq 0, \varrho \geq 0
\end{array}\right.
\end{aligned}
$$

This model could achieve the $w_{j}^{(k)}$ :

$$
w_{j}^{(k)}=\frac{\xi_{j}^{(k)}+\varrho \varsigma_{j}^{(k)}}{\sqrt{\sum_{j=1}^{p}\left(\xi \tau_{j}^{(k)}+\varrho \varsigma_{j}^{(k)}\right)^{2}}} .
$$

The normalization of $w_{j}^{(k)}$ is expressed in the following:

$$
w_{j}^{*(k)}=\frac{w_{j}^{(k)}}{\sum_{j=1}^{p} w_{j}^{(k)}}=\frac{\xi \tau_{j}^{(k)}+\varrho \varsigma_{j}^{(k)}}{\sum_{j=1}^{p}\left(\xi \tau_{j}^{(k)}+\varrho \varsigma_{j}^{(k)}\right)}, \quad j=1,2, \ldots, p .
$$

Step 5. The $k$ th expert's decision matrix is

$$
X_{k}=\left(x_{i j}^{\prime(k)}\right)_{q \times p}=\left[\begin{array}{cccc}
x_{11}^{\prime(k)} & x_{12}^{\prime(k)} & \ldots & x_{1 p}^{\prime(k)} \\
x_{21}^{\prime}(k) & x_{22}^{\prime(k)} & \ldots & x_{2 p}^{\prime(k)} \\
\vdots & \vdots & \ddots & \vdots \\
x_{q 1}^{\prime(k)} & x_{q 2}^{\prime(k)} & \ldots & x_{q p}^{\prime(k)}
\end{array}\right], \quad k \in u
$$

where, for benefit indicators $x_{i j}^{(k)}$, it gives

$$
x_{i j}^{\prime(k)}=\frac{x_{i j}^{(k)}}{\sqrt{\sum_{i=1}^{q}\left(x_{i j}^{(k)}\right)^{2}}}
$$

for cost indicators $x_{i j}^{(k)}$, it gives

$$
x_{i j}^{\prime(k)}=1-\frac{x_{i j}^{(k)}}{\sqrt{\sum_{i=1}^{q}\left(x_{i j}^{(k)}\right)^{2}}} .
$$


Then the calculated indicator weight vector is used to calculate the normalized decision matrix $W=\left(w_{1}, w_{2}, \ldots, w_{u}\right)^{T}:$

$$
X_{k}^{\prime}=\left(w_{j} x_{i j}^{\prime(k)}\right)_{q \times p}=\left[\begin{array}{cccc}
w_{1} x_{11}^{\prime(k)} & w_{2} x_{12}^{\prime(k)} & \ldots & w_{p} x_{1 p}^{\prime(k)} \\
w_{1} x_{21}^{\prime(k)} & w_{2} x_{22}^{\prime(k)} & \ldots & w_{p} x_{2 p}^{\prime(k)} \\
\vdots & \vdots & \ddots & \vdots \\
w_{1} x_{q 1}^{\prime(k)} & w_{2} x_{q 2}^{\prime(k)} & \ldots & w_{p} x_{q p}^{\prime(k)}
\end{array}\right], \quad k \in u .
$$

Then the average matrix of the group decision matrix (denoted as $X^{\prime *}, X^{\prime *}=\frac{1}{u} \sum_{k=1}^{u} X_{k}^{\prime}$ ) is the final result of the indicators.

\subsection{Weights Determination}

As different indicators in the evaluation system may have different impacts on the performance of emergency logistics, it is necessary to lay different importance degrees on various indicators. In this section, an aggregated method with hesitation fuzzy linguistic judgments (i.e., subjective method) and EW (i.e., objective method) is used to obtain the final indicator weights.

\subsubsection{Hesitant Fuzzy Linguistic Judgment Description}

When determining the weights of indicators, experts should be invited first to make linguistic judgments on the importance degree of each indicator. However, each expert has different working experience and knowledge, this difference directly affects their understanding and evaluation of the importance degrees of various indicators [46]. Experts use different linguistic terms when judging the indicators. For example, when experts are confident, they use a single linguistic term to give a clear and definitive assessment, such as "the natural disaster prediction is of the highest importance". However, when they are low in cognition or confident, they would give continuous interval-valued judgments, such as "the material reserve is between medium and important". Some experts give an open range such as "the material transport is more than slightly important", and other experts may offer more flexible judgments such as "the emergency fund reserve is between medium and extremely important, but are most likely to be very important". There is no need to force experts to make crisp/single linguistic/random judgments when they are particularly unfamiliar with certain indicators. Conversely, scoring in this situation may lead to an incorrect result.

Traditional linguistic evaluation approaches that use single linguistic terms are unable to express the hesitations of experts. Therefore, this study applies the method of hesitant fuzzy linguistic term sets [47] to express the expert judgments on the importance degrees of different indicators, as this method is more flexible, accurate, and in line with human habits of information expression [48].

Let $N=\left\{N_{\alpha} \mid \alpha=-t, \ldots,-1,0,1, \ldots, t\right\}$ be a symmetrical linguistic term set, a 9-scale linguistic term set can be expressed in the following:

$$
\begin{aligned}
N= & \left\{N_{\alpha} \mid \alpha=-t, \ldots,-1,0,1, \ldots, t\right\} \\
= & \{\text { extremely poor, very poor, poor, slightly poor, fair, slightly good, good, very good, } \\
& \quad \text { extremely good }\}
\end{aligned}
$$

The linguistic variable $K_{N}(I)$ is denoted as a fuzzy restriction label, and each linguistic value corresponds to a real number in [0,1] [49]. In this paper, a 9-scaled symmetrical linguistic term set is applied for the evaluation [50]: $\{0.0,0.125,0.25,0.375,0.5,0.625,0.75,0.875,1.0\}$. For instance, when evaluating the "material transport route selection", the linguistic information given by hesitant fuzzy linguistic terms might be $\phi_{1}=$ very good, $\phi_{2}=$ between slightly good and very good, $\phi_{3}=$ between poor and fair, probably slight poor $\phi_{4}=$ The performance is no more than slight poor, $\phi_{5}=$ Better than the fair. The real numbers in the interval [0,1] are divided into 9 scales, which can be expressed 
as $K_{N}^{1}=\left\{N_{3}\right\}=\{0.875\}, K_{N}^{2}=\left\{N_{1}, N_{2}\right\}=\{0.625,0.75\}, K_{N}^{3}=\left\{N_{-2}, N_{-1}, N_{0}\right\}=\{0.25,0.375,0.5\}$, $K_{N}^{4}=\left\{N_{-4}, N_{-3}, N_{-2}, N_{-1}\right\}=\{0.0,0.125,0.25,0.375\}, K_{N}^{5}=\left\{N_{0}, N_{1}, N_{2}, N_{3}, N_{4}\right\}=$ $\{0.5,0.625,0.75,0.875,1.0\}$, as shown in Figure 4 .

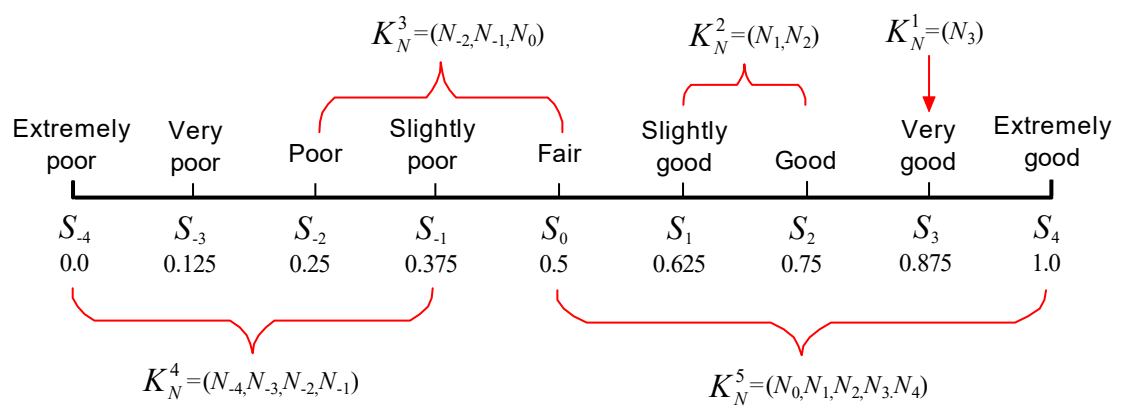

Figure 4. Examples of 9-scale fuzzy linguistic term sets.

The number of various elements in $K_{N}(I)$ can be different, and to compare distances, we must extend the shorter elements until all elements have the same length [23]. The extension value is $\bar{t}=\psi t^{+}+(1-\psi) t^{-}$, where $\psi(0 \leq \psi \leq 1)$ is the parameter obtained by the experts' preferences, $t^{+}$and $t^{-}$are the maximal and minimal values in $K_{N}(I)$, respectively. The extension element value $\bar{t}=1 / 2\left(t^{+}+t^{-}\right)$is used when experts are neutral on elements, which indicates $\psi=1 / 2$. The extension example of hesitant fuzzy linguistic terms set can be seen in Table 2. In addition, when the length of an expert's judgment is 0 , the evaluation value given by other experts is used to supplement it. For example, if the element for $\phi_{6}$ is blank, $\phi_{6}$ is supplemented with all the values given by all the other experts, namely $\phi_{6}=\{0.0,0.125,0.25,0.375,0.5,0.625,0.75,0.875,1.0\}$.

Table 2. Extension example of hesitant fuzzy terms set.

\begin{tabular}{ll}
\hline \multicolumn{1}{c}{ Original Hesitant Fuzzy Terms } & \multicolumn{1}{c}{ Extensions } \\
\hline$K_{N}^{1}=\{0.25\}$ & $\{0.25,0.25,0.25,0.25,0.25\}$ \\
$K_{N}^{2}=\{0.625,0.75,0.875,1.0\}$ & $\{0.625,0.75,0.8125,0.875,1.0\}$ \\
$K_{N}^{3}=\{0.375,0.5,0.625\}$ & $\{0.375,0.5,0.5,0.5,0.625\}$ \\
$K_{N}^{4}=\{0.25,0.375,0.5,0.625,0.75\}$ & $\{0.25,0.375,0.5,0.625,0.75\}$ \\
$K_{N}^{5}=\{0.75,0.875\}$ & $\{0.75,0.8125,0.8125,0.8125,0.875\}$ \\
\hline
\end{tabular}

\subsubsection{Expert Weights Determination}

In the MCDM problems, it is difficult to determine the weight of the expert because each expert has different levels of knowledge, experience, and preferences. Previous studies are more inclined to give equal or fuzzy weights to experts [51,52], while the determination of appropriate expert weights is helpful to improve the reliability of evaluation results [53]. Therefore, a small hesitant degree and a high group consensus are critical to the effectiveness and reliability of the results [18,54]. Therefore, this paper establishes a model of both minimizing degree of hesitation and maximizing group consistency to determine the weight of each expert. Euclidian distance is used to express the divergence between two expert judgments, and the ambiguity of experts in judging the importance degrees of indicators is expressed by the degree of hesitation. The general idea is to minimize the results of the sum of the hesitancy degrees and the Euclidean distance from one expert judgment score to another expert.

In the first place, the importance of each indicator is judged by the experts. The experts' judgments are described by hesitant fuzzy linguistic elements and converted into hesitant fuzzy numbers (extended to the same length $L$ ), which can be expressed as follows:

$$
t_{m h}=\left\{t_{m h}^{l} \mid l=1, \ldots, L, m=1, \ldots, u, h=1, \ldots, p\right\},
$$


where $L$ denotes the length of $t_{m h}$.

As to the importance degree of indicator $A_{h}$, the total Euclidean distance or the judgment divergence between one evaluator and another, can be denoted as $d(t)$ and obtained by

$$
d(t)=\sqrt{\frac{1}{L} \sum_{l=1}^{L} \sum_{m=1}^{u} \sum_{n=1, n \neq m}^{u}\left(t_{m h}^{l}-t_{n h}^{l}\right)^{2}} .
$$

Therefore, hesitant fuzzy judgments with expert weights are: $\left\{w_{m}^{E} t_{m h}^{l} \mid l=1, \ldots, L\right\}$. According to Equation (24), the weighted sum of the total Euclidean distance from one evaluator judgment score to another for the indicator can be defined below:

$$
\bar{d}(t)=\sqrt{\frac{1}{L} \sum_{l=1}^{L} \sum_{m=1}^{u} \sum_{n=1, n \neq m}^{u}\left(w_{m}^{E} t_{m h}^{l}-w_{n}^{E} t_{n h}^{l}\right)^{2}} .
$$

Secondly, the hesitant degree of the linguistic fuzzy sets provided by experts is also measured to obtain the final result with high certainty. The mean of the hesitant fuzzy element $t_{m h}$ can be expressed as follows:

$$
\bar{t}_{m h}=\frac{1}{L} \sum_{l=1}^{L} t_{m h}^{l}
$$

Based on this, the hesitant degree of element $t_{m h}$ can be expressed as

$$
\phi t_{m h}=\sqrt{\frac{1}{L} \sum_{l=1}^{L}\left(t_{m h}^{l}-\bar{t}_{m h}\right)^{2}}=\sqrt{\frac{1}{L} \sum_{l=1}^{L}\left[t_{m h}^{l}-\left(\frac{1}{L} \sum_{l=1}^{L} t_{m h}^{l}\right)\right]^{2}} .
$$

Similarly, the total difference in hesitancy degree between one expert and another can be denoted as follows:

$$
f(\phi t)=\sqrt{\sum_{m=1}^{u} \sum_{n=1, n \neq m}^{u}\left(\phi t_{m h}-\phi t_{n h}\right)^{2}} .
$$

The hesitant degree of expert weight can be represented as $\left\{w_{m}^{E} \phi t_{m h}, m=1,2, \ldots, u, h=\right.$ $1,2, \ldots, p\}$. According to Equation (28), the weighted sum of the hesitancy degrees from one expert assessment to another for an indicator is expressed as follows:

$$
\bar{f}(\phi t)=\sqrt{\sum_{m=1}^{u} \sum_{n=1, n \neq m}^{u}\left(w_{m}^{E} \phi t_{m h}-w_{n}^{E} \phi t_{n h}\right)^{2}} .
$$

To achieve maximum consensus and certainty, we must determine the optimal $w_{m}^{E}(m=1,2, \ldots, u)$ by minimizing the sum of hesitations, based on which the fuzzy hesitations of all expert weights should be brought close to each other as far as possible. According to the former 
analysis, The optimization model for minimizing hesitant degrees and the divergence among experts is presented as follows:

$$
\begin{aligned}
& \min \sum_{h=1}^{p}[\bar{d}(t) \times \bar{f}(\phi t)]=\sum_{h=1}^{p} \sqrt{\frac{1}{L} \sum_{l=1}^{L} \sum_{m=1}^{u} \sum_{n=1, n \neq m}^{u}\left(w_{m}^{E} t_{m h}^{l}-w_{n}^{E} t_{n h}^{l}\right)^{2}} \\
& \times \sqrt{\sum_{m=1}^{u} \sum_{n=1, n \neq m}^{u}\left(w_{m}^{E} \phi t_{m h}-w_{n}^{E} \phi t_{n h}\right)^{2}} \\
& \text { s.t. }\left\{\begin{array}{l}
t_{m h}=\left\{t_{m h}^{l} \mid l=1, \ldots, L, m=1, \ldots, u, h=1, \ldots, p\right\}, \\
t_{n h}=\left\{t_{n h}^{l} \mid l=1, \ldots, L, n=1, \ldots, u, h=1, \ldots, p, n \neq m\right\}, \\
\sum_{m=1}^{u} w_{m}^{E}=1, \\
w_{m}^{E} \geq 0, m=1, \ldots, u .
\end{array}\right.
\end{aligned}
$$

The expert weights $w_{m}^{E}(m=1,2, \ldots, u)$ obtained from model (30) are obtained by minimizing the total sum of Euclidean distances and hesitant degree from one average evaluator judgment score to another, therefore, the determined $w_{m}^{E}(m=1,2, \ldots, u)$ guarantees the consistency and superiority of group decision making.

\subsubsection{Indicator Weights Computation}

The importance of each indicator can be determined by combining the expert hesitant fuzzy judgments with the entropy weight method. As mentioned in the previous section, expert judgments on the importance degrees of indicators can be expressed as $t_{m h}=\{m=1,2, \ldots, u ; h=1,2, \ldots, p\}$. This study employs a weighted average operator to calculate the indicator weights:

Step 1. As the lengths of hesitant fuzzy judgements may not be equal, we must use the extension precedure to ensure all fuzzy judgments have the same length: $t_{m h}=\left\{t_{m h}^{l} \mid l=1,2, \ldots, L ; m=\right.$ $1,2, \ldots, u ; h=1,2, \ldots, p\}$.

Step 2. With the expert weights $w_{m}^{E}(m=1,2, \ldots, u)$ determined from optimization model (30), the weighted and extended hesitant fuzzy judgments can be obtained as follows:

$$
\bar{t}_{m h}=\left\{\left(w_{m}^{E} t_{m h}^{l} \mid l=1,2, \ldots, L ; m=1,2, \ldots, u ; h=1,2 \ldots, p\right\} .\right.
$$

Step 3. Furthermore, the weighted average operator parameters can be calculated using the following formulas:

$$
\begin{gathered}
\bar{\rho}_{h}=\sum_{m=1}^{u} \bar{t}_{m h^{\prime}}^{1} \\
\bar{\sigma}_{h}=\sum_{m=1}^{u} \frac{1}{L-2}\left(\bar{t}_{m h}^{2}+\bar{t}_{m h}^{3}+\ldots+\bar{t}_{m h}^{L-1}\right), \\
\bar{\varsigma}_{h}=\sum_{m=1}^{u} \bar{t}_{m h}^{L} .
\end{gathered}
$$

Step 4. Based on Equations (32)-(34), hesitant fuzzy judgments can be transformed into triangular fuzzy numbers $\left(\bar{\rho}_{h}, \bar{\sigma}_{h}, \bar{\zeta}_{h}\right)$. Similar to de-fuzzification for the intuitionistic fuzzy numbers, the weighted average operator can be utilized to calculate the weight of the $h$ th indicator:

$$
w_{h}^{-}=\frac{\bar{\rho}_{h}+\bar{\zeta}_{h} \times\left(\frac{\bar{\rho}_{h}}{\bar{\rho}_{h}+\bar{\sigma}_{h}}\right)}{\sum_{h=1}^{p}\left[\bar{\rho}_{h}+\bar{\zeta}_{h} \times\left(\frac{\bar{\rho}_{h}}{\bar{\rho}_{h}+\bar{\sigma}_{h}}\right)\right]},
$$


where $w_{h}^{-}$is determined by an optimization model that takes into account the maximum group consensus of experts and the minimum hesitation, and calculated using the weighted average operator.

Hesitant fuzzy linguistic judgments by experts exhibit high subjectivity as it is remarkably affected by expert's knowledge, experience, and preference, while the objective methods such as EW method can make up for the deficiency of the artificial instability of subjective methods in determining indicators, and fully mine the information contained in the original data to obtain more practical results $[2,55,56]$. Therefore, a combination method that incorporates the expert's weight and EW method is presented to determine the indicator weights. The procedure of calculating objective weights based on EW method is listed as follows [57]:

Step 1. Assuming that the original data matrix $R$ is obtained as follows:

$$
R=\left[\begin{array}{cccc}
r_{1,1} & r_{1,2} & \ldots & r_{1, p} \\
r_{2,1} & r_{2,2} & \ldots & r_{2, p} \\
\vdots & \vdots & \ddots & \vdots \\
r_{q, 1} & r_{q, 2} & \ldots & r_{q, p}
\end{array}\right]
$$

Step 2. Then data matrix $R$ is converted into the normalized matrix $O$ as follows:

(1) Normalized matrix of benefit indicators:

$$
a_{i h}=\frac{r_{i h}-\min \left(r_{i h}\right)}{\max \left(r_{i h}\right)-\min \left(r_{i h}\right)},(i=1,2 \ldots, q ; h=1,2 \ldots, p) .
$$

(2) Normalized matrix of cost indicators:

$$
a_{i h}=\frac{\max \left(r_{i h}\right)-r_{i h}}{\max \left(r_{i h}\right)-\min \left(r_{i h}\right)},(i=1,2 \ldots, q ; h=1,2 \ldots, p) .
$$

Step 3. Calculate the entropy value of the $h$ th indicator:

$$
\epsilon_{h}=-\frac{1}{\ln q} \sum_{i=1}^{q} a_{i h} \ln a_{i h}, h=1,2 \ldots, p .
$$

where, if $a_{i h}=0$, then $a_{i h} \ln a_{i h}=0$.

Step 4. Calculate the weight of the indicator as is as below:

$$
w_{h}^{S}=\frac{1-\epsilon_{h}}{p-\sum_{h=1}^{p} \epsilon_{h}}, h=1,2 \ldots, p .
$$

Based on the above description, the final weight of $h$ th indicator (i.e., $w_{h}^{A}$ ) can be determined as follows:

$$
w_{h}^{A}=(1-v) \times w_{h}^{-}+v \times w_{h}^{S}, h=1,2, \ldots, p ，
$$

where the weight for the EW weight is represented by $v$ and $(1-v)$ indicates the weight considering maximum group consensus and minimum hesitant degree. Without loss of generality, the value of $v$ is set as 0.5 in this paper.

\subsection{Relative Closeness to the Ideal Solution Based on TOPSIS}

Considering the complexity and variety of the emergency logistics performance evaluation system, the TOPSIS method's relative closeness computation depends on the scope of available alternatives 
themselves without considering other influence factors, therefore, it is applicable to the regional performance evaluation of emergency logistics.

Based on the above description, as there are indicators $A_{1}, A_{2}, \ldots, A_{p}$, results $r_{i, 1}, r_{i, 2}, \ldots, r_{i, p},(i=1,2, \ldots, q)$ are obtained from regional emergency logistics data. The original evaluation matrix is represented as follows:

$$
R=\left[\begin{array}{cccc}
r_{1,1} & r_{1,2} & \ldots & r_{1, p} \\
r_{2,1} & r_{2,2} & \ldots & r_{2, p} \\
\vdots & \vdots & \ddots & \vdots \\
r_{q, 1} & r_{q, 2} & \ldots & r_{q, p}
\end{array}\right]
$$

In MCDM methods, TOPSIS exploits the positive-ideal solution and the negative-ideal solution in multi-criteria problems to rank the regions (i.e., alternatives).

Step 1. Calculate the normalized decision matrix, the vector normalization is applied to obtain $b_{i h}$ as follows.

$$
b_{i h}=\frac{r_{i h}}{\sqrt{\sum_{i=1}^{q} r_{i h}^{2}}}(i=1,2, \ldots, q) .
$$

Step 2. Obtain the expert weights $w_{m}^{E}(m=1,2, \ldots, u)$ using optimization model (30), and the indicator weights $w_{h}^{A}(h=1,2, \ldots, p)$ are determined according to Equation (41).

Step 3. Construct the weighted and normalized evaluation matrix $Z$ as follows:

$$
\begin{aligned}
Z & =\left[\begin{array}{cccc}
z_{1,1} & z_{1,2} & \ldots & z_{1, p} \\
z_{2,1} & z_{2,2} & \ldots & z_{2, p} \\
\vdots & \vdots & \ddots & \vdots \\
z_{q, 1} & z_{q, 2} & \ldots & z_{q, p}
\end{array}\right] \\
& =\left[\begin{array}{cccc}
w_{1}^{A} b_{1,1} & w_{2}^{A} b_{1,2} & \ldots & w_{p}^{A} b_{1, p} \\
w_{1}^{A} b_{2,1} & w_{2}^{A} b_{2,2} & \ldots & w_{p}^{A} b_{2, p} \\
\vdots & \vdots & \ddots & \vdots \\
w_{1}^{A} b_{q, 1} & w_{2}^{A} b_{q, 2} & \ldots & w_{p}^{A} b_{q, p}
\end{array}\right] .
\end{aligned}
$$

Step 4. Determine the best indicator $\lambda^{+}$and worst indicator $\lambda^{-}$respectively. In this paper, there are both benefit indicators and cost indicators, so some indicators are best when they are close to a specific value (denoted $Z_{f}$ ). Then the new values for these indicators are $\left|Z_{g}-Z_{f}\right|$, where $Z_{g}$ represents the real values. Therefore, the ideal indicator values $\lambda^{+}$and $\lambda^{-}$are determined as

$$
\begin{aligned}
\lambda^{+}= & \left\{\max _{r} z_{i, h} \mid h=1,2, \ldots, p\right\} \\
= & \left(Z_{B_{11}}^{-}, Z_{B_{12}}^{-}, Z_{B_{11}}^{+}, Z_{B_{21}}^{-}, Z_{B_{22}}^{+}, Z_{B_{31}}^{+}, Z_{C_{11}}^{+}, Z_{C_{21}}^{-}, Z_{C_{31}}^{-}, Z_{C_{32}}^{+}, Z_{C_{41}}^{+}\right. \\
& \left.\quad Z_{C_{42}}^{+}, Z_{D_{11}}^{+}, Z_{D_{12}}^{\prime}, Z_{D_{21}}^{+}, Z_{D_{22}}^{+}, Z_{D_{31}}^{+}, Z_{E_{11}}^{-}, Z_{E_{12}}^{+}, Z_{E_{13}}^{-}, Z_{E_{21}}^{+}, Z_{E_{22}}^{-}\right), \\
\lambda^{-}= & \left\{\min _{r} z_{i, h} \mid h=1,2, \ldots, p\right\} \\
= & \left(Z_{B_{11}}^{+}, Z_{B_{12}}^{+}, Z_{B_{13}}^{-}, Z_{B_{21}}^{+}, Z_{B_{22} 2}^{-}, Z_{B_{31}}^{-}, Z_{C_{11}}^{-}, Z_{C_{21}}^{+}, Z_{C_{31}}^{+}, Z_{C_{32}}^{-}, Z_{C_{41}}^{-}\right. \\
& \left.\quad Z_{C_{42}}^{-}, Z_{D_{11}}^{-}, Z_{D_{12}}^{+}, Z_{D_{21}}^{-}, Z_{D_{22}}^{-}, Z_{D_{31}}^{-}, Z_{E_{11}}^{+}, Z_{E_{12}}^{-}, Z_{E_{13}}^{+}, Z_{E_{21}}^{-}, Z_{E_{22}}^{+}\right),
\end{aligned}
$$

where $z_{h}^{+}=\max _{i} z_{i, h}, h=1,2, \ldots, p, z_{h}^{-}=\min _{i} z_{i, h}, h=1,2, \ldots, p$. 
Step 5. Obtain the Euclidean distance between each region (i.e., alternative) and $\lambda^{+}$as follows:

$$
U_{i}^{+}=\sqrt{\sum_{h=1}^{p}\left(z_{i . h}-z_{h}^{+}\right)^{2}}, i=1,2, \ldots, q .
$$

Similarly, the Euclidean distance between each region (i.e., alternative) and $\lambda^{-}$can be determined by

$$
U_{i}^{-}=\sqrt{\sum_{h=1}^{p}\left(z_{i . h}-z_{h}^{-}\right)^{2}}, i=1,2, \ldots, q .
$$

Step 6. Compute the relative closeness of each region (i.e., alternative) to the most preferable $\lambda^{+}$ using the following formula:

$$
Y_{i}^{+}=\frac{U_{i}^{-}}{U_{i}^{+}+U_{i}^{-}}, 0<Y_{i}^{+}<1, i=1,2, \ldots, q .
$$

Step 7. Rank the alternatives (i.e., regions) by sorting $Y_{i}^{+}(i=1,2, \ldots, q)$ in descending order as $Y_{i}^{+}$can serve as the evaluation score of the emergency logistics performance. In other words, the higher value of $Y_{i}^{+}$indicates better regional emergency logistics performance.

\section{Case Study}

\subsection{Case Description}

The occurrence of public emergencies usually has disastrous consequences, and its suddenness and destructiveness have brought great challenges to human beings. There have been more than 200 earthquakes in China in the past two decades. On 12 May 2008, the 8.0-magnitude Wenchuan Earthquake occurred in Sichuan, China. The event was China's worst massive earthquake in the previous six decades in China, causing more than 70,000 fatalities, 18,000 missing, and 370,000 injured with around 4.8 million people becoming homeless [58]. This incident has brought unprecedented challenges to the Chinese government and the public in China. The suddenness and destruction of the earthquake fully tested the ability of China to deal with unconventional emergencies.

In this study, the evaluation method is employed to 5 worst-hit regions of the 2008 Wenchuan Earthquake, including Wenchuan County (denoted as W), Shifang City (denoted as S), Mianzhu City (denoted as $M$ ), Beichuan County (denoted as $B$ ) and Qingchuan County (denoted as $Q$ ). The study area is shown in Figure 5. By evaluating the performance of emergency logistics in these regions, this paper provides feasible suggestions for the public to deal with unconventional emergencies. 


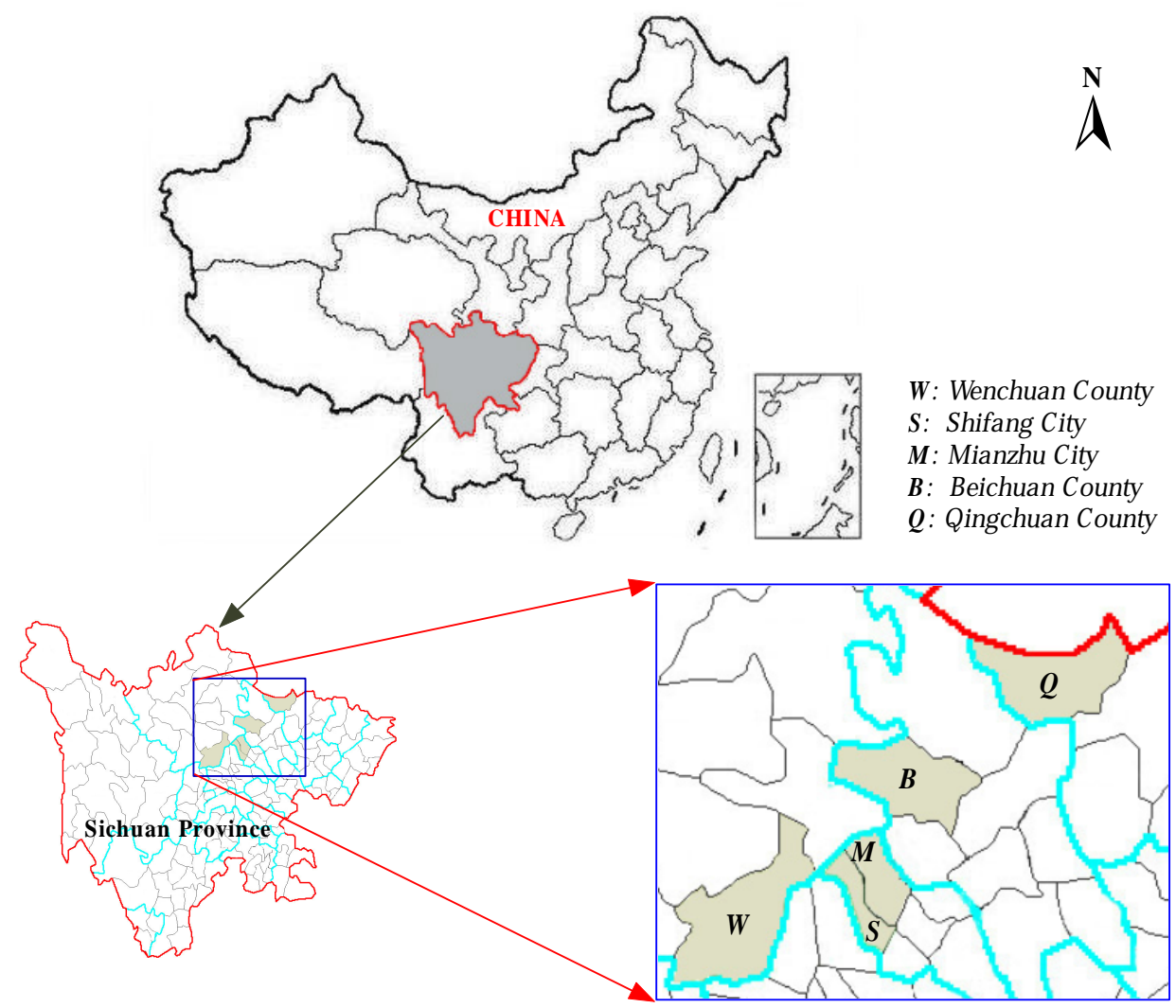

Figure 5. Location of the study area.

\subsection{Data Source}

The indicators data of each region mainly come from the China Statistical Yearbook, China Knowledge Resource Integrated Database, and local government websites.

In this evaluation system, some indicators are difficult to directly obtain accurate values, such as the real-time road condition information collected after an earthquake of one city. As a result, a more effective approach may be to use linguistic judements instead of numerical values. This paper uses MGLA information $[28,29]$ to solve the quantification of these indicators. Firstly, the multi-granularity linguistic comparison matrices are transformed and unified using the computational formula. Secondly, the method of mean and standard deviation is applied to calculate the indicator's weight vectors with reference to the different decision-makers. Finally, the average matrix of the group decision matrix is obtained by computing the normalized decision matrix based on the determined weight vector of each indicator [28].

\subsection{Result Interpretation}

Three experts $E=\left\{e_{1}, e_{2}, e_{3}\right\}$ are local emergency logistics management experts, who make evaluations based on their actual situation and working experience. They are asked to evaluate indicators $\left(B_{13}, B_{22}, C_{32}, C_{41}, C_{42}\right.$ and $\left.D_{22}\right)$ that were difficult to quantify in the study. The 3 multi-granularity linguistic term sets are presented as follows:

$S_{y}^{5}=\left\{S_{-2}^{5}=\right.$ very poor, $S_{-1}^{5}=$ poor,$S_{0}^{5}=$ medium, $S_{1}^{5}=$ good, $S_{2}^{5}=$ very good $\}$.

$S_{y}^{7}=\left\{S_{-3}^{7}=\right.$ very poor,$S_{-2}^{7}=$ poor,$S_{-1}^{7}=$ slightly poor, $S_{0}^{7}=$ medium, $S_{1}^{7}=$ slightly good, $S_{2}^{7}=$ good, $S_{3}^{7}=$ very good $\}$.

$S_{y}^{9}=\left\{S_{-4}^{9}=\right.$ extremely poor,$S_{-3}^{9}=$ very poor, $S_{-2}^{9}=$ poor,$S_{-1}^{9}=$ slightly poor,$S_{0}^{9}=$ medium, $S_{1}^{9}=$ slightly good, $S_{2}^{9}=$ good, $S_{3}^{9}=$ very good, $S_{4}^{9}=$ extremely good $\}$. 
Three experts give their evaluation information shown in Tables 3-5. According to Equations (7)-(10), the evaluation information of the three experts can be transformation and unified into 9 granularity evaluation matrices as shown in Tables 6-8. Using Equations (12) and (14), we can get:

$$
\begin{gathered}
\tau_{j}^{(1)}=(2.0396,1.4967,1.2649,2.0396,1.7889,1.2649), \\
\tau_{j}^{(2)}=(0.9978,1.0667,0.9978,0.8433,1.8856,0.8433), \\
\tau_{j}^{(3)}=(0.8000,0.6325,1.0198,1.8547,1.4697,1.3582), \\
\varsigma_{j}^{(1)}=(1.7600,1.2800,0.8000,1.7600,1.6000,0.8000), \\
\varsigma_{j}^{(2)}=(0.8533,0.9600,0.8533,0.5333,1.6000,0.5333), \\
\varsigma_{j}^{(3)}=(0.7200,0.4000,0.8800,1.6800,1.3600,1.1200) .
\end{gathered}
$$

Using Equation (18) to compute the indicators weight reference to different experts $e_{k}(k=1,2,3)$, supposing that $\xi=\varrho=0.5$, then we can get:

$$
\begin{aligned}
& w^{*(1)}=(0.2123,0.1552,0.1154,0.2123,0.1894,0.1154), \\
& w^{*(2)}=(0.1547,0.1693,0.1547,0.1150,0.2913,0.1150), \\
& w^{*(3)}=(0.1143,0.0777,0.1429,0.2659,0.2129,0.1863) .
\end{aligned}
$$

Use Equations (19)-(21) to normalize the decision matrix of expert $e_{k}$ as follows:

$$
\begin{gathered}
X_{1}=\left[\begin{array}{cccccc}
0.6220 & 0 & 0.3780 & 0 & 0.5 & 0.7559 \\
0 & 0.3162 & 0 & 0.7559 & 0.5 & 0.3780 \\
0.3780 & 0.3162 & 0.7559 & 0.6220 & 0 & 0.3780 \\
0.3780 & 0.6325 & 0.3780 & 0.3780 & 0.5 & 0 \\
0.7559 & 0.6325 & 0.3780 & 0.3780 & 0.5 & 0.3780
\end{array}\right], \\
X_{2}=\left[\begin{array}{cccccc}
0 & 0.5 & 0.3162 & 0.7559 & 0 & 0.3780 \\
0.4226 & 0.2500 & 0.6325 & 0.3780 & 0.6838 & 0 \\
0.5774 & 0.7500 & 0.6325 & 0.3780 & 0.3675 & 0.3780 \\
0.5774 & 0.2500 & 0.3162 & 0 & 0.3162 & 0.7559 \\
0 & 0.2500 & 0 & 0.3780 & 0.6325 & 0.3780
\end{array}\right], \\
X_{3}=\left[\begin{array}{cccccc}
0.2500 & 0.4264 & 0.4082 & 0.4714 & 0.8018 & 0.3162 \\
0.7500 & 0.4264 & 0.5981 & 0.5286 & 0.5345 & 0 \\
0.5 & 0.6396 & 0 & 0.2357 & 0 & 0.3162 \\
0.25 & 0.2132 & 0.8165 & 0 & 0.7327 & 0.3675 \\
0.2500 & 0.4264 & 0 & 0.2929 & 0 & 0.6325
\end{array}\right] .
\end{gathered}
$$

Using Equation (22) to get the weighted standardized evaluation matrices as follows:

$$
X_{1}^{\prime}=\left(w_{j} x_{i j}^{\prime(k)}\right)_{q \times p}=\left[\begin{array}{cccccc}
0.1321 & 0 & 0.0436 & 0 & 0.0947 & 0.0872 \\
0 & 0.0491 & 0 & 0.1605 & 0.0947 & 0.0436 \\
0.0803 & 0.0491 & 0.0872 & 0.1321 & 0 & 0.0436 \\
0.0803 & 0.0981 & 0.0436 & 0.0803 & 0.0947 & 0 \\
0.1605 & 0.0981 & 0.0436 & 0.0803 & 0.0947 & 0.0436
\end{array}\right],
$$




$$
\begin{aligned}
& X_{2}^{\prime}=\left[\begin{array}{cccccc}
0 & 0.0847 & 0.0489 & 0.0870 & 0 & 0.0435 \\
0.0654 & 0.0423 & 0.0978 & 0.0435 & 0.1992 & 0 \\
0.0893 & 0.1270 & 0.0978 & 0.0435 & 0.1070 & 0.0435 \\
0.0893 & 0.0423 & 0.0489 & 0 & 0.0921 & 0.0870 \\
0 & 0.0423 & 0 & 0.0435 & 0.1842 & 0.0435
\end{array}\right], \\
& X_{3}^{\prime}=\left[\begin{array}{cccccc}
0.0286 & 0.0331 & 0.0583 & 0.1253 & 0.1707 & 0.0589 \\
0.0858 & 0.0331 & 0.0855 & 0.1406 & 0.1138 & 0 \\
0.0572 & 0.0497 & 0 & 0.0627 & 0 & 0.0589 \\
0.0286 & 0.0166 & 0.1167 & 0.0000 & 0.1560 & 0.0685 \\
0.0286 & 0.0331 & 0 & 0.0779 & 0 & 0.1178
\end{array}\right] .
\end{aligned}
$$

The average matrix of the group decision matrix:

$$
X^{*}=\left[\begin{array}{cccccc}
0.0536 & 0.0393 & 0.0503 & 0.0708 & 0.0885 & 0.0632 \\
0.0504 & 0.0415 & 0.0611 & 0.1148 & 0.1359 & 0.0145 \\
0.0756 & 0.0753 & 0.0617 & 0.0794 & 0.0357 & 0.0487 \\
0.0660 & 0.0523 & 0.0697 & 0.0268 & 0.1143 & 0.0518 \\
0.0630 & 0.0579 & 0.0145 & 0.0672 & 0.0930 & 0.0683
\end{array}\right] .
$$

After all the indicators values are obtained, the indicator importance is evaluated. The assessment team consists of five experts (i.e., $E_{1}, E_{2}, \ldots, E_{5}$ ), the experts invited for this paper are emergency logistics decision-makers experienced in emergency allocation and evaluation, and they make linguistic judgements about the importance of each indicator according to his own experience. The five experts' hesitant fuzzy judgments on the importance degree of each indicator are shown in Table 9. The expert hesitant fuzzy judgments of unequal length are extended to the same length. Lingo software is used to solve model (30), and the expert weights are computed as $w_{m}^{E}=\{0.1989,0.1975,0.2141,0.1898,0.1996\}$. Next, we use the objective weight of EW calculation to adjust the subjective weight of experts. On that basis, the TOPSIS-EW method is used to calculate $Y_{i}^{+}$, the rank results obtained can be seen in Table 10 . According to the proposed method, the five regions in the earthquake received performance ratings of V, III, I, II, and IV.

Table 3. 5 granularity linguistic decision matrix given by expert $e_{1}$.

\begin{tabular}{ccccccc}
\hline & $\boldsymbol{B}_{\mathbf{1 3}}$ & $\boldsymbol{B}_{\mathbf{2 2}}$ & $\boldsymbol{C}_{\mathbf{3 2}}$ & $\boldsymbol{C}_{\mathbf{4 1}}$ & $\boldsymbol{C}_{\mathbf{4 2}}$ & $\boldsymbol{D}_{\mathbf{2 2}}$ \\
\hline$W$ & $S_{-1}^{5}$ & $S_{0}^{5}$ & $S_{1}^{5}$ & $S_{0}^{5}$ & $S_{1}^{5}$ & $S_{2}^{5}$ \\
$B$ & $S_{0}^{5}$ & $S_{1}^{5}$ & $S_{0}^{5}$ & $S_{2}^{5}$ & $S_{-1}^{5}$ & $S_{1}^{5}$ \\
$Q$ & $S_{1}^{5}$ & $S_{1}^{5}$ & $S_{2}^{5}$ & $S_{-1}^{5}$ & $S_{0}^{5}$ & $S_{1}^{5}$ \\
$M$ & $S_{1}^{5}$ & $S_{2}^{5}$ & $S_{1}^{5}$ & $S_{1}^{5}$ & $S_{-1}^{5}$ & $S_{0}^{5}$ \\
$S$ & $S_{2}^{5}$ & $S_{2}^{5}$ & $S_{1}^{5}$ & $S_{1}^{5}$ & $S_{1}^{5}$ & $S_{1}^{5}$ \\
\hline
\end{tabular}

Table 4. 7 granularity linguistic decision matrix given by expert $e_{2}$.

\begin{tabular}{ccccccc}
\hline & $\boldsymbol{B}_{\mathbf{1 3}}$ & $\boldsymbol{B}_{\mathbf{2 2}}$ & $\boldsymbol{C}_{\mathbf{3 2}}$ & $\boldsymbol{C}_{\mathbf{4 1}}$ & $\boldsymbol{C}_{\mathbf{4 2}}$ & $\boldsymbol{D}_{\mathbf{2 2}}$ \\
\hline$W$ & $S_{0}^{7}$ & $S_{2}^{7}$ & $S_{1}^{7}$ & $S_{2}^{7}$ & $S_{0}^{7}$ & $S_{1}^{7}$ \\
$B$ & $S_{-1}^{7}$ & $S_{1}^{7}$ & $S_{2}^{7}$ & $S_{1}^{7}$ & $S_{7}^{7}$ & $S_{0}^{7}$ \\
$Q$ & $S_{1}^{7}$ & $S_{3}^{7}$ & $S_{2}^{7}$ & $S_{1}^{7}$ & $S_{-2}^{7}$ & $S_{1}^{7}$ \\
$M$ & $S_{1}^{7}$ & $S_{1}^{7}$ & $S_{1}^{7}$ & $S_{0}^{7}$ & $S_{1}^{7}$ & $S_{2}^{7}$ \\
$S$ & $S_{0}^{7}$ & $S_{1}^{7}$ & $S_{0}^{7}$ & $S_{1}^{7}$ & $S_{2}^{7}$ & $S_{1}^{7}$ \\
\hline
\end{tabular}


Table 5. 9 granularity linguistic decision matrix given by expert $e_{3}$.

\begin{tabular}{ccccccc}
\hline & $\boldsymbol{B}_{\mathbf{1 3}}$ & $\boldsymbol{B}_{\mathbf{2 2}}$ & $\boldsymbol{C}_{\mathbf{3 2}}$ & $\boldsymbol{C}_{\mathbf{4 1}}$ & $\boldsymbol{C}_{\mathbf{4 2}}$ & $\boldsymbol{D}_{\mathbf{2 2}}$ \\
\hline$W$ & $S_{1}^{9}$ & $S_{2}^{9}$ & $S_{1}^{9}$ & $S_{2}^{9}$ & $S_{3}^{9}$ & $S_{1}^{9}$ \\
$B$ & $S_{3}^{9}$ & $S_{2}^{9}$ & $S_{-1}^{9}$ & $S_{-2}^{9}$ & $S_{2}^{9}$ & $S_{0}^{9}$ \\
$Q$ & $S_{2}^{9}$ & $S_{3}^{9}$ & $S_{0}^{9}$ & $S_{1}^{9}$ & $S_{0}^{9}$ & $S_{1}^{9}$ \\
$M$ & $S_{1}^{9}$ & $S_{1}^{9}$ & $S_{2}^{9}$ & $S_{0}^{9}$ & $S_{-1}^{9}$ & $S_{-2}^{9}$ \\
$S$ & $S_{1}^{9}$ & $S_{2}^{9}$ & $S_{0}^{9}$ & $S_{-3}^{9}$ & $S_{0}^{9}$ & $S_{2}^{9}$ \\
\hline
\end{tabular}

Table 6. 9 granularity linguistic decision matrix given by expert $e_{1}$ after transformation.

\begin{tabular}{ccccccc}
\hline & $\boldsymbol{B}_{\mathbf{1 3}}$ & $\boldsymbol{B}_{\mathbf{2 2}}$ & $\boldsymbol{C}_{\mathbf{3 2}}$ & $\boldsymbol{C}_{\mathbf{4 1}}$ & $\boldsymbol{C}_{\mathbf{4 2}}$ & $\boldsymbol{D}_{\mathbf{2 2}}$ \\
\hline$W$ & $S_{-2}^{9}$ & $S_{0}^{9}$ & $S_{2}^{9}$ & $S_{0}^{9}$ & $S_{2}^{9}$ & $S_{4}^{9}$ \\
$B$ & $S_{0}^{9}$ & $S_{2}^{9}$ & $S_{0}^{9}$ & $S_{4}^{9}$ & $S_{-2}^{9}$ & $S_{2}^{9}$ \\
$Q$ & $S_{2}^{9}$ & $S_{2}^{9}$ & $S_{4}^{9}$ & $S_{-2}^{9}$ & $S_{0}^{9}$ & $S_{2}^{9}$ \\
$M$ & $S_{2}^{9}$ & $S_{4}^{9}$ & $S_{2}^{9}$ & $S_{2}^{9}$ & $S_{-2}^{9}$ & $S_{0}^{9}$ \\
$S$ & $S_{4}^{9}$ & $S_{4}^{9}$ & $S_{2}^{9}$ & $S_{2}^{9}$ & $S_{2}^{9}$ & $S_{2}^{9}$ \\
\hline
\end{tabular}

Table 7. 9 granularity linguistic decision matrix given by expert $e_{2}$ after transformation.

\begin{tabular}{ccccccc}
\hline & $\boldsymbol{B}_{\mathbf{1 3}}$ & $\boldsymbol{B}_{\mathbf{2 2}}$ & $\boldsymbol{C}_{\mathbf{3 2}}$ & $\boldsymbol{C}_{\mathbf{4 1}}$ & $\boldsymbol{C}_{\mathbf{4 2}}$ & $\boldsymbol{D}_{\mathbf{2 2}}$ \\
\hline$W$ & $S_{0}^{9}$ & $S_{8 / 3}^{9}$ & $S_{4 / 3}^{9}$ & $S_{8 / 3}^{9}$ & $S_{0}^{9}$ & $S_{4 / 3}^{9}$ \\
$B$ & $S_{-4 / 3}^{9}$ & $S_{4 / 3}^{9}$ & $S_{8 / 3}^{9}$ & $S_{4 / 3}^{9}$ & $S_{-4 / 3}^{9}$ & $S_{0}^{9}$ \\
$Q$ & $S_{4 / 3}^{9 / 3}$ & $S_{4}^{9}$ & $S_{8 / 3}^{9}$ & $S_{4 / 3}^{9}$ & $S_{-8 / 3}^{9}$ & $S_{4 / 3}^{9}$ \\
$M$ & $S_{4 / 3}^{9}$ & $S_{4 / 3}^{9}$ & $S_{4 / 3}^{9}$ & $S_{0}^{9}$ & $S_{4 / 3}^{9}$ & $S_{8 / 3}^{9}$ \\
$S$ & $S_{0}^{9}$ & $S_{4 / 3}^{9}$ & $S_{0}^{9}$ & $S_{4 / 3}^{9}$ & $S_{8 / 3}^{9}$ & $S_{4 / 3}^{9}$ \\
\hline
\end{tabular}

Table 8. 9 granularity linguistic decision matrix given by expert $e_{3}$ after transformation.

\begin{tabular}{ccccccc}
\hline & $\boldsymbol{B}_{\mathbf{1 3}}$ & $\boldsymbol{B}_{\mathbf{2 2}}$ & $\boldsymbol{C}_{\mathbf{3 2}}$ & $\boldsymbol{C}_{\mathbf{4 1}}$ & $\boldsymbol{C}_{\mathbf{4 2}}$ & $\boldsymbol{D}_{\mathbf{2 2}}$ \\
\hline$W$ & $S_{1}^{9}$ & $S_{2}^{9}$ & $S_{1}^{9}$ & $S_{2}^{9}$ & $S_{3}^{9}$ & $S_{1}^{9}$ \\
$B$ & $S_{3}^{9}$ & $S_{2}^{9}$ & $S_{-1}^{9}$ & $S_{-2}^{9}$ & $\mathrm{~d} S_{2}^{9}$ & $S_{0}^{9}$ \\
$Q$ & $S_{2}^{9}$ & $S_{3}^{9}$ & $S_{0}^{9}$ & $S_{1}^{9}$ & $S_{0}^{9}$ & $S_{1}^{9}$ \\
$M$ & $S_{1}^{9}$ & $S_{1}^{9}$ & $S_{2}^{9}$ & $S_{0}^{9}$ & $S_{-1}^{9}$ & $S_{-2}^{9}$ \\
$S$ & $S_{1}^{9}$ & $S_{2}^{9}$ & $S_{0}^{9}$ & $S_{-3}^{9}$ & $S_{0}^{9}$ & $S_{2}^{9}$ \\
\hline
\end{tabular}

Table 9. Expert fuzzy judgments to the importance of indicators.

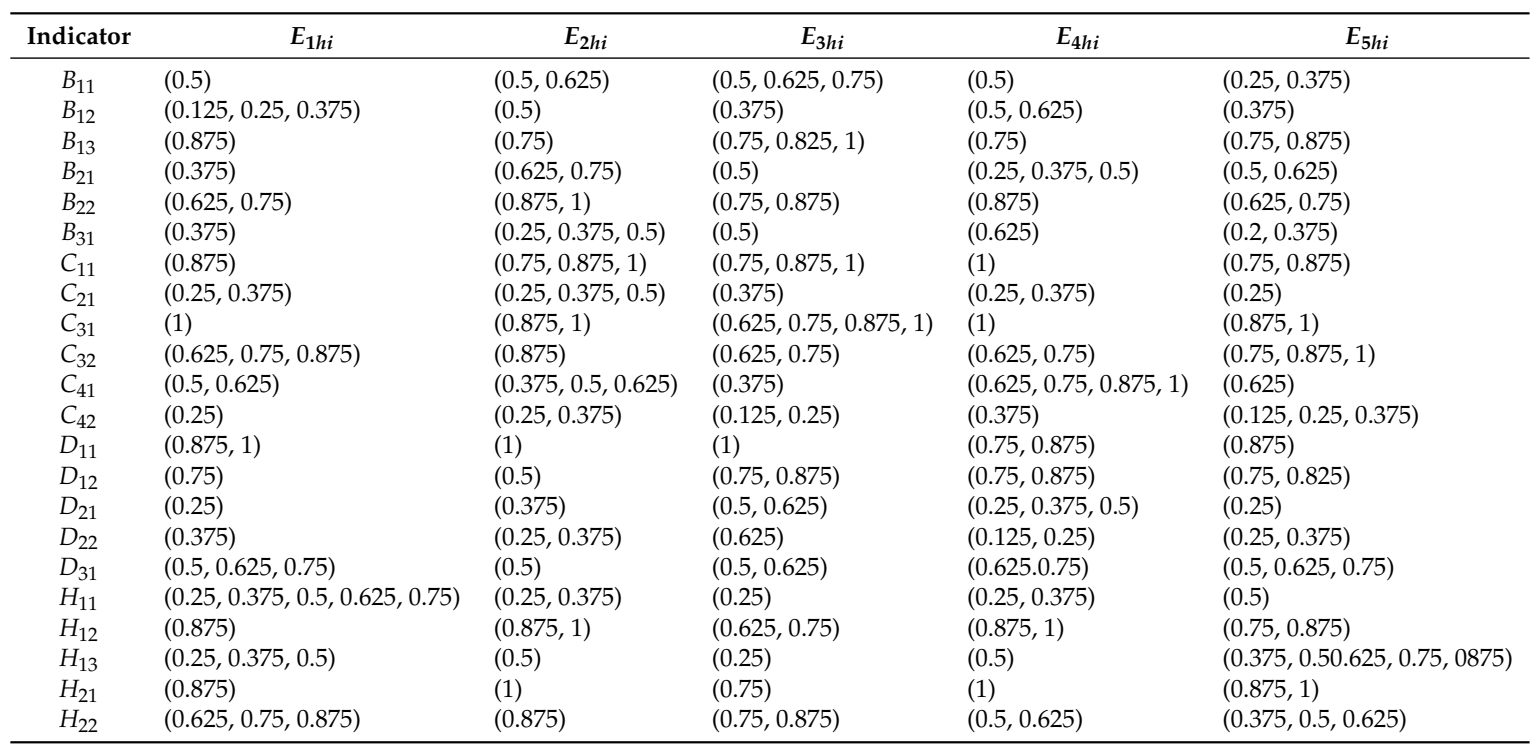


Table 10. Evaluation results and comparison analysis.

\begin{tabular}{ccccccc}
\hline \multirow{2}{*}{ Region } & \multicolumn{2}{c}{ Fuzzy TOPSIS-EW Method } & \multicolumn{2}{c}{ TOPSIS-EW Method } & \multicolumn{2}{c}{ TOPSIS Method with Equal Expert Weights } \\
\cline { 2 - 7 } & $\boldsymbol{Y}_{i}^{+}$ & Rank by $\boldsymbol{Y}_{i}^{+}$ & $\boldsymbol{Y}_{i}^{\prime}{ }^{+}$ & Rank by $\boldsymbol{Y}_{i}^{\prime+}$ & $\boldsymbol{Y}_{\boldsymbol{i}}^{\prime \prime}$ & Rank by $\boldsymbol{Y}_{\boldsymbol{i}}^{\prime \prime}+$ \\
\hline$W$ & 0.0971 & V & 0.0793 & V & 0.1178 & V \\
$B$ & 0.4465 & III & 0.5118 & II & 0.3584 & III \\
$Q$ & 0.8906 & I & 0.9083 & I & 0.8696 & I \\
$M$ & 0.4518 & II & 0.4002 & III & 0.5159 & II \\
$S$ & 0.2012 & IV & 0.2273 & IV & 0.1727 & IV \\
\hline
\end{tabular}

\subsection{Comparison Analysis}

$Y_{i}^{\prime}{ }^{+}(i=1,2, \ldots, 5)$ represents the relative closeness of the $i$ th region evaluated by the TOPSIS-EW method, in which the expert assessments on the importance of the degrees of the indicators is ignored. The results of the comparison analysis between the fuzzy TOPSIS-EW method proposed in this paper and the TOPSIS-EW method are shown in Table 10. Compared with $Y_{i}^{+}$based on the symmetrical method of fuzzy TOPSIS-EW, except for Beichuan County and Mianzhu City, the rankings of other regions remain unchanged, while the relative closeness is slightly different. One of the reasons for this difference is that the EW method can directly reflect the information of the original data, but it can not take into account the expert judgments on the importance degrees of the indicators. For example, Mianzhu City storage cost of emergency supplies is nearly four times that of Beichuan County, which is very important from the perspective of the EW principle, but experts think it is not so important. Therefore, $Y_{i}^{+}$which takes into account the subjective influences is more persuasive than $Y_{i}^{\prime+}$.

$Y_{i}^{\prime \prime}+(i=1,2, \ldots, 5)$ represents the evaluation results of the $i$ th region by TOPSIS with equal expert weights. Compared with $Y_{i}^{+}$based on the symmetrical method of fuzzy TOPSIS-EW, the relative closenesses of all regions (i.e., alternatives) change. The reason for this difference is that different experts have different experience and knowledge when evaluating the importance of indicators, we must pay attention to the difference in importance of each expert, while the equal expert weight method ignores this aspect. Therefore, the model (30) of maximizing group consistency and certainty proposed in the fuzzy TOPSIS-EW method of this paper can better solve this problem, with the objective value is 0.7362 which is better than the result by the TOPSIS method with equal expert weights (i.e., 0.7533). Therefore, the method put forward in this paper is more reliable.

To sum up, just considering the subjective factors or the objective factors, the determined weights cannot be regarded reasonable, only by taking into account both of these two aspects, we can get more effective and reliable weights and get more reasonable evaluation results.

\subsection{Sensitivity Analysis}

In the fuzzy TOPSIS-EW method, parameter $v$ is represented as a preference parameter for subjective and objective weights. Generally speaking, the value of $v$ is often set as 0.5 . However, $v$ can be any number between 0 and 1 . Therefore, it is necessary to perform sensitivity analysis on the parameter $v$ to verify the results, sensitivity analysis can be conducted from totally considering the subjective factor (i.e., $v=0$ ) to totally considering the objective factor (i.e., $v=1$ ). The relevant results according to $v$ value can be found in Figure 6. It is shown in Figure 6 that with the variation of $v$ value, the relative closeness of each region changes. The performance rankings of Qingchuan County, Shifang City, and Wenchuan County are relatively stable, whereas those of Beichuan County and Mianzhu City have changed. The results show that when only subjective or objective weight is considered, the ranking results of performance levels in different regions will be different, so this bias must be carefully considered in practical problems. 


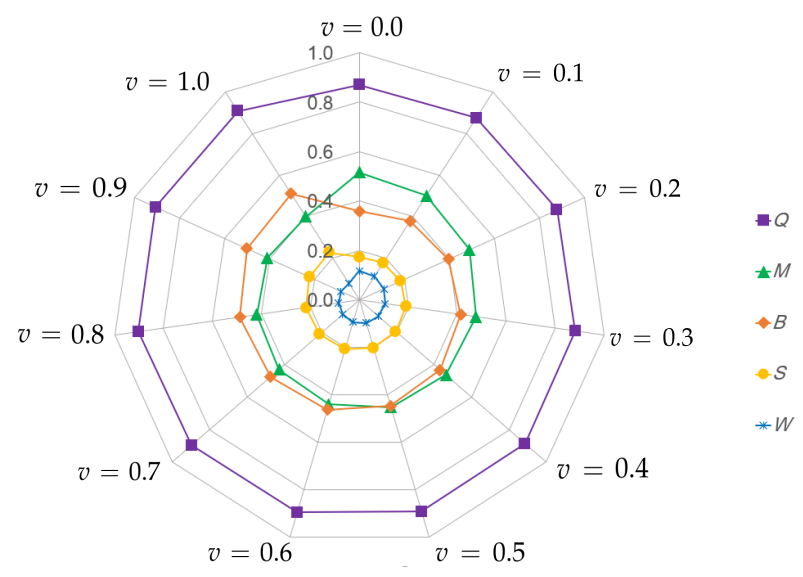

Figure 6. Sensitivity analysis on parameter $v$.

\subsection{Managerial Suggestions}

The analysis results based on the value of $Y_{i}^{+}$show that Qingchuan county has the best performance and Wenchuan County has the worst. $Y_{i}^{+}$value $\{0-0.2,0.2-0.4,0.4-0.6,0.6-0.8$, $0.8-1\}$, corresponding performance level is \{poor, relatively poor, average, relatively good, good\}. Therefore, as can be shown in Table 10. In this earthquake, Qingchuan County's emergency logistics performance is good, Mianzhu City and Beichuan County had average performance, emergency logistics performances in Shifang City is relatively poor, and the Wenchuan County had poor performance. Compared with the EW method and equal expert weight evaluation results, The fuzzy TOPSIS-EW method considers both subjective weight and objective weight, and with the higher group consensus so the relative closeness of all regions has changed. Therefore $Y_{i}^{+}$evaluation results are more accurate and reliable than the $Y_{i}^{\prime+}$ and $Y_{i}^{\prime \prime}{ }^{+}$.

In this case analysis, some key problems are highlighted. First, the actual supply of emergency supplies is far below the quantity need, and the distribution of supplies is unreasonable. For example, before 25 May, Wenchuan County, which had the largest number of people affected, received less than 15 percent of the number of tents in Qingchuan County. Secondly, the long time it took the government to get initial information about the disaster, especially in Qingchuan County, Mianzhu City and Shifang City, reduced the efficiency of emergency logistics decision-making. Thirdly, The efficiency of material transportation and material distribution after the disaster was low. Therefore, the paper puts forward some suggestions to improve the emergency logistics system and improve regional emergency logistic performance.

(1) Increasing emergency material reserves. After the disaster, the disaster area is in urgent need of adequate supplies of life support. However, the actual amount of materials is always in short supply, affecting the follow-up relief work. In addition, reducing the storage space and saving storage costs can also improve relief work efficiency.

(2) Improving the informatization of emergency logistics management. it is advised to accelerate the speed of information acquisition and apply advanced information and communication technology to improve the speed and accuracy of pre-disaster prediction, material transportation, and information transmission, and further improve the speed of information transportation command and dispatch and emergency response. For example, it took several hours for Qingchuan County to obtain information about the disaster, which seriously affected the timeliness of disaster relief activities.

(3) Strengthening the construction of contingency logistics plans. Firstly, it is needed to rehearse the emergency logistics plan, improve the practical operation ability of professionals, and increase the emergency response ability. In addition, what should be done is to test, revise, and improve the emergency plan, and more effectively deal with sudden and complex emergencies in practice. 
(4) Improving a cross-departmental and cross-regional linkage and cooperation mechanism. For the first time after the disaster, all departments should formulate a common code of action and strengthen mutual communication and cooperation to ensure that personnel and materials can reach the emergency site as quickly and safely as possible. For example, the Wenchuan County and Beichuan County after the earthquake set up an emergency response working group later than the other three areas.

\section{Conclusions and Future Research Direction}

The basic proposition of this research is that the occurrence of public emergencies are inevitable, so ensuring efficient emergency logistics capacity can mitigate the consequences of disasters. The MCDM method proposed in this paper provides an appropriate method for the performance evaluation of emergency logistics, some inspiration for increasing the ability of emergency logistics resilience are derived. The main contributions of this study are as follows: (1) Comprehensive consideration of the three stages of the emergency preparation, response, and recovery indicators system, based on which a more comprehensive evaluation indicator system of the emergency logistics performance is established. (2) The MCDM method (i.e., the fuzzy TOPSIS-EW method) with MGLA information is used to solve some indicators that are difficult to be quantified in the indicator system. (3) A hesitancy degree minimized divergence model is constructed to determine the weight of the experts, so as to achieve the maximum group consensus and reliability evaluation results. And apply the EW method to adjust subjective weights assigned by experts. This fuzzy TOPSIS-EW method synthetizes the merits of subjective and objective factors, thus improving the impartiality and reliability of the evaluation results. (4) A practical case study is conducted on the Wenchuan earthquake in China, which is the worst earthquake in China in recent years. Using the proposed method, the five regions (i.e., Wenchuan County, Beichuan County, Qingchuan County, Mianzhu City, and Shifang City) in the earthquake receive performance ratings of V, III, I, II, and IV. Moreover, a comparison analysis using the proposed method with the TOPSIS-EW method and TOPSIS method with equal expert weight is conducted, it verifies the reliability of the proposed method considering both subjective weight and objective weight, which is also demonstrated by a sensitivity analysis on parameter $v$ illustrating the preference degree on subjective/objective weight. Finally, on the basis of case analysis, some concrete suggestions are put forward to improve the performance of emergency logistics.

The limitations of this paper and future research direction include the following aspects. First of all, this paper does not focus on the distance calculation formula of experts divergence and relative closeness of TOPSIS. Therefore, in future studies, we can improve the distance calculation formula, such as using Mahalanobis distance and Hamming distance. Moreover, due to the complexity of MCDM, the TOPSIS-DEA method, TOPSIS-ANP method, grey relational analysis, VIKOR, and AHP can be used to increase its stability in future studies. Finally, the proposed evaluation method can also be applied to the evaluation of public emergencies such as the evaluation and decision-making in the the COVID-19 Global Pandemic and the flood disaster in southern China in 2020, which is conducive to the sustainable development of public health and public safety.

Author Contributions: Conceptualization, Y.L. and Y.T.; data curation, Y.T. and L.L.; formal analysis, Y.T., L.L., and Y.M.; investigation, Y.T. and L.L.; methodology, Y.T., L.L., and Y.M.; supervision, Y.L. and Y.T.; writing-original draft, L.L.; writing-review \& editing, Y.T. All authors have read and agreed to the published version of the manuscript.

Funding: This research was funded by the National Natural Science Foundation of China (grant number 71801177), the Humanities and Social Science Fund of Ministry of Education of China (grant number 18YJC630163), the China Postdoctoral Science Foundation (grant number 2019M662732) and the Fundamental Research Funds for the Central Universities (grant numbers WUT: 2020VI006, WUT: 2020VI008, 2019GYZX019).

Conflicts of Interest: The authors declare no conflict of interest. 


\section{References}

1. Zhou, L.; Wu, X.; Xu, Z.; Fujita, H. Emergency decision making for natural disasters: An overview. Int. J. Disaster Risk Reduct. 2018, 27, 567-576. [CrossRef]

2. Ma, F.; He, J.; Ma, J.; Xia, S. Evaluation of urban green transportation planning based on central point triangle whiten weight function and entropy-AHP. Transp. Res. Procedia 2017, 25, 3638-3648. [CrossRef]

3. Pamucar, D.; Deveci, M.; Canitez, F.; Lukovac, V. Selecting an airport ground access mode using novel fuzzy LBWA-WASPAS-H decision making model. Eng. Appl. Artif. Intell. 2020, 93. [CrossRef]

4. Zhang, Z.; Wang, L.; Wang, Y. An emergency decision making method for different situation response based on game theory and prospect theory. Symmetry 2018, 10, 476. [CrossRef]

5. Ozdamar, L.; Ekinci, E.; Kucukyazici, B. Emergency logistics planning in natural disasters. Ann. Oper. Res. 2004, 129, 217-245. [CrossRef]

6. Wang, L.; Song, J.; Shi, L. Dynamic emergency logistics planning: models and heuristic algorithm. Optim. Lett. 2015, 9, 1533-1552. [CrossRef]

7. Hu, S.; Dong, Z.S. Supplier selection and pre-positioning strategy in humanitarian relief. Omega Int. J. Manag. Sci. 2019, 83, 287-298. [CrossRef]

8. Roni, M.S.; Jin, M.; Eksioglu, S.D. A hybrid inventory management system responding to regular demand and surge demand. Omega Int. J. Manag. Sci. 2015, 52, 190-200. [CrossRef]

9. Zhang, J.; Liu, H.; Yu, G.; Ruan, J.; Chan, F.T.S. A three-stage and multi-objective stochastic programming model to improve the sustainable rescue ability by considering secondary disasters in emergency logistics. Comput. Ind. Eng. 2019, 135, 1145-1154. [CrossRef]

10. Sahu, A.K.; Datta, S.; Mahapatra, S.S. Evaluation and selection of resilient suppliers in fuzzy environment exploration of fuzzy-VIKOR. Benchmarking Int. J. 2016, 23, 651-673. [CrossRef]

11. Bozorgi-Amiri, A.; Khorsi, M. A dynamic multi-objective location-routing model for relief logistic planning under uncertainty on demand, travel time, and cost parameters. Int. J. Adv. Manuf. Technol. 2016, 85, 1633-1648. [CrossRef]

12. Liu, T.; Song, Y.; Liu, J. Evaluation on distribution integrity of emergency supplies. In Proceedings of the 14th Internatioal Conference on Innovation and Management, Swansea, Wales, 27-29 September 2017; Volumes I \& II, pp. 584-588. [CrossRef]

13. Gong, B.; Chen, X.; Hu, C. Fuzzy entropy clustering approach to evaluate the reliability of emergency logistics system. Energy Procedia 2012, 16, 278-283, doi:10.1016/j.egypro.2012.01.046.

14. Guan, X.; Qian, L.; Li, M.; Chen, H.; Zhou, L. Earthquake relief emergency logistics capacity evaluation model integrating cloud generalized information aggregation operators. J. Intell. Fuzzy Syst. 2017, 32, 2281-2294. [CrossRef]

15. Zhang, Z.; Liu, C.; Yang, L. Evaluation research of emergency logistics system based on set pair analysis model. In Proceedings of the 2009 Fourth International Conference on Cooperation and Promotion of Information Resources in Science and Technology, Beijing, China, 21-23 November 2009; pp. 327-332. [CrossRef]

16. Tofighi, S.; Torabi, S.A.; Mansouri, S.A. Humanitarian logistics network design under mixed uncertainty. Eur. J. Oper. Res. 2016, 250, 239-250. [CrossRef]

17. Boonmee, C.; Arimura, M.; Asada, T. Facility location optimization model for emergency humanitarian logistics. Int. J. Disaster Risk Reduct. 2017, 24, 485-498. [CrossRef]

18. Li, Z.; Zhang, Q.; Liao, H. Efficient-equitable-ecological evaluation of regional water resource coordination considering both visible and virtual water. Omega Int. J. Manag. Sci. 2019, 83, 223-235. [CrossRef]

19. Liu, Y.; Jin, L.; Zhu, F. A Multi-Criteria Group Decision Making Model for Green Supplier Selection under the Ordered Weighted Hesitant Fuzzy Environment. Symmetry 2019, 11, 17. [CrossRef]

20. Dogan, O.; Deveci, M.; Canitez, F.; Kahraman, C. A corridor selection for locating autonomous vehicles using an interval-valued intuitionistic fuzzy AHP and TOPSIS method. Soft Comput. 2019, 24, 8937-8953. [CrossRef]

21. Özcan, T.; Çelebi, N.; Esnaf, Ş. Comparative analysis of multi-criteria decision making methodologies and implementation of a warehouse location selection problem. Expert Syst. Appl. 2011, 38, 9773-9779. [CrossRef]

22. Wa̧tróbski, J.; Jankowski, J.; Ziemba, P.; Karczmarczyk, A.; Zioło, M. Generalised framework for multi-criteria method selection. Omega Int. J. Manag. Sci. 2019, 86, 107-124. [CrossRef] 
23. Liao, H.; Xu, Z.; Zeng, X. Distance and similarity measures for hesitant fuzzy linguistic term sets and their application in multi-criteria decision making. Inf. Sci. 2014, 271, 125-142. [CrossRef]

24. Liao, H.; Xu, Z.; Zeng, X. Qualitative decision making with correlation coefficients of hesitant fuzzy linguistic term sets. Knowl. Based Syst. 2015, 76, 127-138. [CrossRef]

25. Zhang, Z.; Guo, C.; Luis, M. Managing multigranular linguistic distribution assessments in large-scale multiattribute group decision making. IEEE Trans. Syst. Man Cybern. 2017, 47, 3063-3076. [CrossRef]

26. Li, Z.; Liechty, M.; Xu, J.; Lev, B. A fuzzy multi-criteria group decision making method for individual research output evaluation with maximum consensus. Knowl. Based Syst. 2014, 56, 253-263. [CrossRef]

27. Zhang, C.; Wang, C.; Zhang, Z. A novel technique for multiple attribute group decision making in interval-valued hesitant fuzzy environments with incomplete weight information. J. Ambient. Intell. Humaniz. Comput. 2019, 10, 2429-2445. [CrossRef]

28. Liu, S.; Chan, F.T.S.; Ran, W. Multi-attribute group decision-making with multi-granularity linguistic assessment information: An improved approach based on deviation and TOPSIS. Appl. Math. Model. 2013, 37, 10129-10140. [CrossRef]

29. Zhang, Z.; Guo, C. A method for multi-granularity uncertain linguistic group decision making with incomplete weight information. Knowl. Based Syst. 2012, 26, 111-119. [CrossRef]

30. Morente-Molinera, J.A.; Pérez, I.J.; Ureña, M.R.; Herrera-Viedma, E. On multi-granular fuzzy linguistic modeling in group decision making problems: A systematic review and future trends. Knowl. Based Syst. 2015, 74, 49-60. [CrossRef]

31. Wang, H.; Xu, Z.; Zeng, X. Linguistic terms with weakened hedges: A model for qualitative decision making under uncertainty. Inf. Sci. 2018, 433, 37-54. [CrossRef]

32. Schneider, J.; Romanowski, C.J.; Stein, K. Decision making to support local emergency preparation, response, and recovery. In Proceedings of the 2013 IEEE International Conference on Technologies for Homeland Security (HST), Waltham, MA, USA, 12-14 November 2013; pp. 498-503. [CrossRef]

33. Turcanu, C.; Crouäil, P.; Duranova, T.; Camps, J.; Schneider, T.; Raskob, W. Training courses on emergency preparedness, response and recovery: theory, practice and application of newly developed tools. Radioprotection 2016, 51, S171-S173. [CrossRef]

34. Wang, X.; Cui, Q.; Li, S. An optimal water allocation model based on water resources security assessment and its application in Zhangjiakou Region, northern China. Resour. Conserv. Recycl. 2012, 69, 57-65. [CrossRef]

35. Li, D. Depth Research of Emergency Logistics Management information systems. In Proceedings of the 5th International Conference on Education, Management, Information and Medicine (EMIM), Shenyang, China, 24-26 April 2015; pp. 972-976. [CrossRef]

36. Yandong, W.; Shisi, R.; Teng, W.; Mengling, Q. Rapid estimation of an earthquake impact area using a spatial logistic growth model based on social media data. Int. J. Digit. Earth 2018, 12, 1265-1284. [CrossRef]

37. Havenith, H.B.; Strom, A.; Torgoev, I.; Torgoev, A.; Lamair, L.; Ischuk, A.; Abdrakhmatov, K. Tien Shan geohazards database: earthquakes and landslides. Geomorphology 2015, 249, 16-31. [CrossRef]

38. Bastos, M.A.G.; Campos, V.B.G.; de Mello Bandeira, R.A. Logistic processes in a post-disaster relief operation. Procedia Soc. Behav. Sci. 2014, 111, 1175-1184. [CrossRef]

39. Sheu, J.B. An emergency logistics distribution approach for quick response to urgent relief demand in disasters. Transp. Res. Part Logist. Transp. Rev. 2007, 43, 687-709. [CrossRef]

40. Zhang, J.; Zhao, Q. Partition of emergency materials reserve area and analysis of reserve pattern. In Proceedings of the 3rd International Conference on Logistics, Informatics and Service Science, Beijing, China, 21-24 August 2015; pp. 335-340. [CrossRef]

41. Axsäter, S. A heuristic for triggering emergency orders in an inventory system. Eur. J. Oper. Res. 2007, 176, 880-891. [CrossRef]

42. Balcik, B.; Beamon, B.M.; Smilowitz, K. Last mile distribution in humanitarian relief. J. Intell. Transp. Syst. 2008, 12, 51-63. [CrossRef]

43. Li, X.; Su, G.; Zhong, S.; Zhang, F.; Zhang, F.; Huang, C.; Yuan, H.; Huang, Q.; Chen, J. Study on scene-driven emergency drill method. Pract. Appl. Intell. Syst. 2014, 1089-1097. [CrossRef]

44. Wang, X.; Xiong, W. An integrated linguistic-based group decision-making approach for quality function deployment. Expert Syst. Appl. 2011, 38, 14428-14438. [CrossRef]

45. Xu, Y.; Da, Q. Standard and mean deviation methods for linguistic group decision making and their applications. Expert Syst. Appl. 2010, 37, 5905-5912. [CrossRef] 
46. Li, Z.; Xu, J.; Lev, B.; Gang, J. Multi-criteria group individual research output evaluation based on context-free grammar judgments with assessing attitude. Omega Int. J. Manag. Sci. 2015, 57, 282-293. [CrossRef]

47. Liao, H.; Gou, X.; Xu, Z.; Zeng, X.; Herrera, F. Hesitancy degree-based correlation measures for hesitant fuzzy linguistic term sets and their applications in multiple criteria decision making. Inf. Sci. 2020, 508, 275-292. [CrossRef]

48. Yan, H.; Ma, T.; Huynh, V. On qualitative multi-attribute group decision making and its consensus measure: A probability based perspective. Omega Int. J. Manag. Sci. 2017, 70, 94-117. [CrossRef]

49. Gao, J.; Xu, Z.; Liang, Z.; Liao, H. Expected consistency-based emergency decision making with incomplete probabilistic linguistic preference relations. Knowl. Based Syst. 2019, 176, 15-28. [CrossRef]

50. Meng, F.; Tang, J. New ranking order for linguistic hesitant fuzzy sets. J. Oper. Res. Soc. 2019, 70, 531-540. [CrossRef]

51. Rathi, R.; Khanduja, D.; Sharma, S.K. A fuzzy-MADM based approach for prioritising Six Sigma projects in the Indian auto sector. Int. J. Manag. Sci. Eng. Manag. 2017, 12, 133-140. [CrossRef]

52. Zhang, S.; Liu, S. A GRA-based intuitionistic fuzzy multi-criteria group decision making method for personnel selection. Expert Syst. Appl. 2011, 38, 11401-11405. [CrossRef]

53. Dong, Y.; Liu, Y.; Liang, H.; Chiclana, F.; Enrique, H. Strategic weight manipulation in multiple attribute decision making. Omega Int. J. Manag. Sci. 2018, 75, 154-164. [CrossRef]

54. Thuong, N.T.H.; Zhang, R.; Li, Z.; Hong, P.T.D. Multi-criteria evaluation of financial statement quality based on hesitant fuzzy judgments with assessing attitude. Int. J. Manag. Sci. Eng. Manag. 2018, 13, 254-264. [CrossRef]

55. Han, Q.; Li, W.; Song, Y.; Zhang, T.; Wang, R. A new method for MAGDM based on improved TOPSIS and a novel pythagorean fuzzy soft entropy. Symmetry 2019, 11, 905. [CrossRef]

56. Mohsen, O.; Fereshteh, N. An extended VIKOR method based on entropy measure for the failure modes risk assessment-A case study of the geothermal power plant (GPP). Saf. Sci. 2017, 92, 160-172. [CrossRef]

57. Xu, H.; Ma, C.; Lian, J.; Xu, K.; Chaima, E. Urban flooding risk assessment based on an integrated k-means cluster algorithm and improved entropy weight method in the region of Haikou, China. J. Hyderol. 2018, 563, 975-986. [CrossRef]

58. Liu, Q.; Ruan, X.; Shi, P. Selection of emergency shelter sites for seismic disasters in mountainous regions: Lessons from the 2008 Wenchuan Ms 8.0 Earthquake, China. J. Asian Earth Sci. 2011, 40, 926-934. [CrossRef]

(C) 2020 by the authors. Licensee MDPI, Basel, Switzerland. This article is an open access article distributed under the terms and conditions of the Creative Commons Attribution (CC BY) license (http://creativecommons.org/licenses/by/4.0/). 